Portland State University

PDXScholar

1974

\title{
Survey on Dropouts from Graduate Schools of Social Work, 1970-1972
}

William J. Hadley

Portland State University

Vard R. Miller

Portland State University

Michael C. Prange

Portland State University

Follow this and additional works at: https://pdxscholar.library.pdx.edu/open_access_etds

Part of the Social Work Commons

Let us know how access to this document benefits you.

\section{Recommended Citation}

Hadley, William J.; Miller, Vard R.; and Prange, Michael C., "Survey on Dropouts from Graduate Schools of Social Work, 1970-1972" (1974). Dissertations and Theses. Paper 1726.

https://doi.org/10.15760/etd.1725

This Thesis is brought to you for free and open access. It has been accepted for inclusion in Dissertations and Theses by an authorized administrator of PDXScholar. Please contact us if we can make this document more accessible: pdxscholar@pdx.edu. 
SURVEY ON DROPOUTS FROM GRADUATE

SCHOOLS OF SOCIAL WORK, 1970- 1972

by

William J. Hadley

Vard R. Miller

Michael C. Prange

A practicum submitted in partial fullfillment of the requirements for the degree of

MASTER OF SOCIAL WORK

Portland State University

1974 

LIST OF TABLES

INTRODUCTION

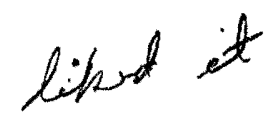

\section{CHAPTER}

I METHODOLOGY..................... 3

II ANALYSIS AND SUMMARY.............. 11

III CRITIQUE $\ldots \ldots \ldots \ldots \ldots \ldots \ldots \ldots \ldots \ldots \ldots \ldots \ldots \ldots \ldots \ldots \ldots \ldots$

IV RECOMMENDATIONS................. 66

\section{A PPENDICES}

A Frequency and Range of Dropout Population For All

Responding Schools.................... 69

B Ethnic Characteristics ................. 71

Table 1 Ethnic Characteristics of Enrolled and Dropout Students From A'ccredited Schools (1970 to 1972), Excluding the University of Puerto Rico

Table 2 Proportion of Dropout to Enrolled Students by Ethnicity (1970 to 1972), Excluding the University of Puerto Rico

C General Data on Dropouts with and without the University

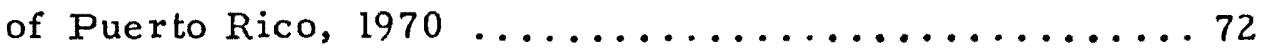

D General Data on Dropouts with and without the University of Puerto Rico, $1971 \ldots \ldots \ldots \ldots \ldots \ldots \ldots \ldots \ldots$

E General Data on Dropouts with and without the University

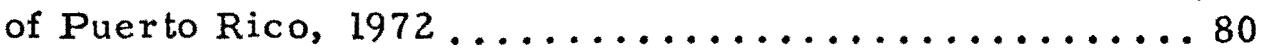


TABLE OF CONTENTS, Con't.

page

F Questionnaire Information and Instructions.... $84 \mathrm{w}$

G Sample Questionnaire.............. 89 
TABLE

page

$\begin{array}{lll}\text { TABLE } & \text { I } & \text { Schools Polled } \\ \text { TABLE } & \text { II } & \text { Frequency Distribution of Schools Reporting - }\end{array}$ According to Size

TABLE III Total Dropouts by Year with Accredited and Non-Accredited Schools

According to Size
TABLE III Total Dropouts by Year with Accredited and
Non-Accredited Schools

TABLE IV Total Enrolling Students and Dropouts Excluding Non-Accredited Schools
TABLE V Dropout Rates by Year
TABLE VI Comparison of Total Enrollment and Dropouts by Class Year
TABLE VII Dropout Rate by Year and Class
TABLE VIII Comparison of Enrolled and Dropouts by Class in 1970

TABLE IX Comparison of Enrolled and Dropouts by Class in 1971

TABLE $X \quad$ Comparison of Enrolled and Dropouts by Class in 1972

TABLE XI Comparison of Total Dropouts and Enrolled by Sex

TABLE XII Comparison of Dropouts and Enrolled by Sex in 1970

TABLE XIII Comparison of Dropouts and Enrolled by Sex in 1971

TABLE XIV Comparison of Dropouts and Enrolled by Sex in 19.72

TABLE XV Yearly Drop Proportion of the Enrolled Populations by Sex 
TABLE XVI Age Breakdown and Comparison of Dropouts and Enrolled Population, 1971-1972 Combined

TABLE XVII Age Breakdown of Dropouts in 1970

TABLE

XVIII

Age Breakdown and Comparison of Dropouts and Enrolled Population in 1971

TABLE XIX Age Breakdown and Comparison of Dropouts and Enrolled Population in 1972

TABLE $\quad X X \quad$ Ethnic Characteristics of Dropouts

TABLE

XXI

Ethnic Characteristics of Enrolled Students and Dropouts for CSWE Accredited Schools $1970-1972$

TABLE

XXII Ethnic Characteristics of Enrolled Students and Dropouts for 25 CSWE Accredited Schools in 1970

TABLE

XXIII Ethnic Characteristics of Enrolled Students and Dropouts for 27 CSWE Accredited Schools in 1971

TABLE

XXIV Ethnic Characteristics of Enrolled Students and Dropouts for 29 CSWE Accredited Schools in 1972

TABLE

XXV. Percentages of Dropouts for Each Ethnic Catagory by Year

TABLE

XXVI Dropouts and Enrolled Students Receiving Financial Grants in 1971 and 1972

TABLE XXVII Marital Status of Dropouts - Totals

TABLE XXVIII Marital Status of Dropouts by Year

TABLE XXIX Family Size of Dropouts - Totals

TABLE XXX Family Size of Dropouts by Year 
LIST OF TABLES Con't.

TABLE XXXI Type of Concentration of Dropouts - Totals 47

TABLE XXXII Type of Concentration of Dropouts by Year 48

TABLE XXXIII Previous Social Work Experience of Dropouts 49

TABLE XXXIV Previous Social Work Experience of Dropouts by Year 50

TABLE XXXV Employment Status of Dropouts 51

TABLE XXXVI Residential Status of Dropouts - Totals 52

TABLE XXXVII Residential Status of Dropouts by Year 53

TABLE XXXVIII Reasons for Dropping Out 56 


\section{INTRODUCTION}

This research project has been designed as an initial exploratory survey of dropouts from graduate schools of social work. The target population was those students who had dropped from graduate schools of social work accredited by the Council on Social Work Education. The time frame covered a three year period from 1970 to 1972 . The data was gathered through the development and administration of a survey instrument in questionnaire form.

Our initial interest and involvement in this project was generated by a request from Jack C. Finley, Director of Admissions, Portland Sta te University, School of Social Work. Mr. Finley was concerned over the recent dropout rates at Portland State's School of Social Work and how they compared to other schools of social work.
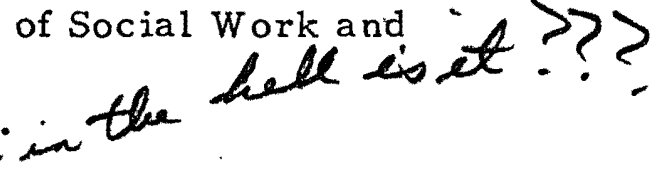
A review of the literature provided no relevant information. It

was evident that the area of social work dropouts had not recieved due attention and therefore, a need for data existed. We decided that the primary intent of the survey was to compile data on demographic characteristics and reasons for dropping out. Where possible comparisons with enrolled student populations would be made utilizing the Annual Statistics on Sacial Work Education as a comparison base. A secondary purpose 
was to assess trends and rates within the dropout population. This type of information could indicate areas warranting further study while also developing a fundamental body of knowledge on social work dropouts.

The following body of the survey report is divided into four major sections. They are in order, Methodology, Analysis and Summary, Critique, and Recommendations.

Methodology Methodology presents in chronological order the major tasks performed in completing the survey. It includes determining the focus of the survey, developing the means of obtaining information, methods of data compilation, and methods of reporting findings.

Analysis The Analysis section reports key survey findings, dropout data, trends, comparisons, and a summary of findings.

Critique The Critique phase of the reportassess the merits, difficulties and shortcomings of the survey.

Recommendations The final section of the report makes recommendations on possibilities for further study and clarification of findings.

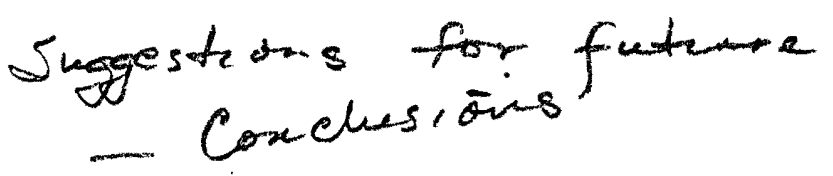




\section{METHODOLOGY}

Determination of Scope

After deciding to undertake a study of dropouts from graduate schools of social work, the parameters of the area studied had to be determined. To facilitate this process, several sources were examined.

The initial investigation began at the Graduate Admissions Department of the Portland State University School of Social Work. Mr. Finley has been Director of Admissions for three years and has frequent contact with his counterparts at other schools. From Mr. Finley, we obtained some impressions about dropouts in general and information about Portland State dropouts in particular. Although no comprehensive data was available at P.S. U., we were able to form some ideas about the range of variables that might be included in the study.

The second step in narrowing the scope was to poll P.S.U. School of Social Work faculty about variables they felt were important in considering dropout rates. Their ideas were collected by sending a questionnaire to all faculty members. A two week period was allowed in which written responses could be returned to the research group. At the end of this period we received ten completed questionnaires out of 25 sent. 
In some instances we met with individual faculty members who responded to the poll and further discussed their ideas. The information was synthesized and duplicate areas eliminated. Certain variables recommended for study were then added to the existing list of variables under consideration.

The third step in defining the parameters was to review the literature regarding dropouts and related areas. A search was made of the general Social Work literature and specifically publications by the Council on Social Work Education. 1 This review proved rather fruitless since very little data was found regarding trends, characteristics, and the numbers of dropouts from schools of Social Work. This lack of information influenced the focus of our study giving impetus to a nationwide study of dropouts, assessing trends and frequencies, which could be meaningful to social work education.

The final step was to weigh all of the ideas and information to ar rive at a decision on the variables that would be appropriate to such a study. In determining the final content and scope of the project, we again discussed our ideas with Mr. Finley and also Dr. Frank Miles, Chairman of the research sequence at P.S.U. . The purpose of this meeting was to assess the feasability and limitations of our proposal.

IThe publications studied included: Journal on Social Work Education, CSWE Reporter, and The Annual Statistics on Graduate Social Work Education in the United States. 
Focus of Study

From the foregoing process we arrived at the focus of the study. All graduate schools of social work education, accredited by the Council on Social Work Education, would be polled to gather information on dropouts. Data on demographic characteristics of dropouts and reasons for dropping would be explored for a three yeâr period, 1970 through 1972. Our aim was to determine from data collected the total number of dropouts and rate for the entire study period, total dropouts and rates for each year and total dropouts and rates for each school responding for each year. Frequencies of response to demographic variables and reasons for dropping out would also be presented in the same format as dropout rates.

Seventy seven CSWE accredited graduate schools of social work in the United States and Puerto Rico in 1972 comprised the sample population. The study would seek data over a three year period, including the first year class of 1970, and the first and second year classes of 1971 and 1972. Trends in the dropout rates would be established by comparing yearly totals of dropout respondents to the overall student population characteristics presented in Statistics on Social Work Education. With CSWE material used as a population base, rates could easily be established by school, by year, etc.

The data obtained by this study would be presented in a general manner rather than attempting to determine causal relationships between 
variables. Since the intent of this study is to gather preliminary information, any attempt to assess causal relationships would exceed the scope of the study.

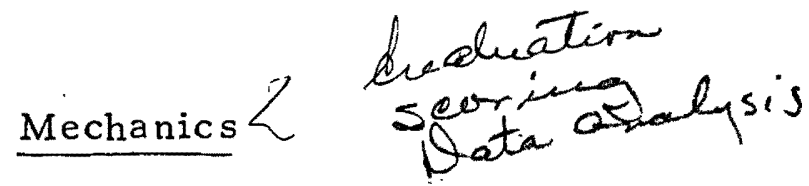

From the preliminary assessment phase of the study, the research group developed a set of variables to be explored. These variables were then subdivided into demographic characteristics and reasons given for dropping out. To gather the necessary information a check list questionnaire was developed. The instrument was designed as a questionnaire which could be completed on each student who dropped out. This design would facilitate additional comparitive analysis in subsequent examination of data on individual students. ${ }^{2}$ The number of questionnaires mailed to each school equalled 10 percent of it's total enrolled population. This number proved sufficient except for one school. The directions included instruction for obtaining additional questionnaires in the event more were required.

Questionnaires and accompanying materials were addressed to the directors of admissions of the seventy-seven schools, requesting that the admissions director or his designee fill out the questionnaires. Each packet included: a cover letter, set of directions, a set of definitions, an appropriate number of questionnaires, and a stamped return

${ }^{2}$ See Appendix G for sample questionnaire. 
addressed envelope for completed questionnaires. ${ }^{3}$

Description of Questionnaire

The questionnaire was developed as a check-box instrument so the respondent could indicate his choice of the appropriate catagory by placing a mark in the space provided. 4 The left hand margin was large enough for responses to be coded by the research group. Each $8-1 / 2$ by 14 inch page contained questionnaires for two separate students. Each individual questionnaire was subdivided into two major parts; demographic characteristics of the dropout and stated reasons for dropping out. Also each questionnaire was assigned a coded school number and an individual code number. This coding system allowed grouping of dropouts without violating the confidentiality of individuals or schools. The design also permitted factoring by any single variable within either section of the questionnaire.

The section on demographic characteristics sought data in the following areas: year program began, year dropped, sex, age, ethnicity, marital status, number of children (if any), type of concentration in school, social work experience prior to admission to graduate school, employment while in school, financial grants, and residency.

${ }^{3}$ See Appendix $\mathrm{F}$ for sample copy of information and instructions sent to schools.

${ }^{4}$ See Appendix G for sample questionnaire. 
The second section, "Reasons for Dropping Out", listed a series of possible choices which students could have stated as reasons for dropping out. These choices included the areas of : financial reasons, personal adjustment reasons, academic reasons, health reasons, pregnancies, dissatisfaction with the profession of social work, dissatisfaction with graduate school curriculum, lack of future employt ment in the field, and a section for other reasons not already listed. All variables explored were developed by the research group in the preliminary phase of the study.

Administering Questionnaire

School packets were mailed on October 15, 1973, with instructions that refusals to reply or completed questionnaires to be mailed to Portland State University within 30 days of receipt of the school-questionnaire packet. As a low response rate was anticipated at the end of the 30 day period, a follow up letter was developed to encourage completion of the questionnaires. Aiter waiting an additional 28 days, a follow up letter was sent to all schools that had not responded by that date. The follow up letter asked that all refusals (or) responses be mailed to the school no later than January 15, 1974. The extra time was allowed because of the schools being closed during the Christmas Holidays.

Compilation of Data from Questionnaires 
After the school packets had been sent, a coding schedule was devised to code the returned questionnaires. Some questionnaires were completed and returned within the 30 day period. These were coded upon arrival and additional coding catagories were created as needed. For coding "Other, specify" responses.

The next step in the data compilation process was to transfer the coded material from each questionnaire to a standard IBM 80 field punch card. The cards were punched and verified while a computer tally program was being developed. Dr. Dean Clarkson, a Regional Research Institute employee and school faculty member, assisted the research group in deciding how to group the data and tallies on individual characteristics.

The first computer tally was made, gathering totals for each catagory on the questionnaire. These totals were assessed to ascertain feasibility of grouping school responses. At this time it was decided which additional data would be gathered on the second tally.

The second computer program was devised so that responses would be grouped by two sets of factors, the school years 1970, 1971, and 1972 and by individual schools. As a result the research group received a second set of print outs with responses grouped by year for each school. Thus a set of data was generated listing the number of respondents for each variable and then percentages, by school for 1970, 1971, and 1972 . 
10

Additional Data Sources

To develop a population base for comparison with dropouts, the group members manually tallied selected information from the annual CSWE Statistics for the years 1970, 1971, and 1972. Enrollment data was compiled on class, class year, sex, age groupings, ethnicity, grants and concentration. This included the number and percent in each catogory. From the onset it was planned to use CSWE figures as a comfanion source and specific items on the questionnaire utilized CSWE wording and categories to facilitate this process.

The final methodological task was the development of an outline for presentation which became the working format for the report.

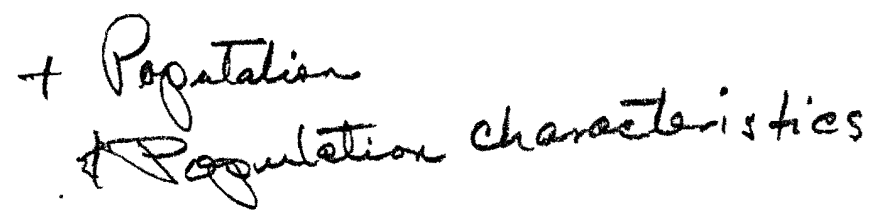




\section{ANALYSIS AND SUMMARY}

Before presenting our findings from the questionnaires, some general information must be presented. Of the 77 Council of Social Work Education accredited schools polled, 30 returned completed questionnaires and another 16 sent letters of refusal. This number represents 59.8 percent of total schools polled, with 40.3 percent not responding in any fashion. The 20.8 percent refusal rate is important and will be discussed in a later segment of the report.

\section{TABLE I}

Schools Polled

Returned Completed Questionnaire

Refused to Respond

No Response
N Percent

$30 * 39$

$16 \quad 20.8$

$31 \quad 40.3$

Totals $\quad 77 \quad 100 \%$

* Of the 30 schools returning a completed questionnaire

(one school's questionnaires had to be deleted due to

inconsistencies in reporting)

The 29 schools whose data will be reported had total enrolled 
populations ranging in size from 72 to 300 students in 1972.

\section{TABLE II}

\section{Frequency Distribution of School Reporting According to Size}

1972 Student Population*

Under 100

$100-125$

$125-150$

$150-175$

$175-200$

$200-225$

$225-250$

$250-275$

$275-300$
$\underline{N}$

3

5

3

4

7

3

1

2

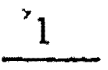

29

* Data from Statistics on Graduate Social Work Education, 1972, includes both first and second year students.

From the preceeding table it can be seen that the highest number of responses occurred in the schools with student populations of 225 or less. General population characteristics cannot be inferred from the responses of the 29 schools as they are not a representative sample of all schools. None of the eight schools with student populations of 400 and over responded. Our Sample included 25 schools with a population of 225 or less. 
These schools represent 47.2 percent of all schools wi thin that population range. However, this sample was not randomly selected and cannot be deemed a representative sample of schools with a population of 225 or less.

The foregoing does not invalidate our findings but puts them in a different perspective. Rather than being viewed in terms of their inferential value they must be seen as general indicators of dropout characteristics and trends. This does not detract from the validity of the data as applied to the 29 responding schools.

The following section will exhibit the findings on each variable. For each of these catagories overall totals, totals by years and comparisons will be presented.

For the purposes of this paper a dropout will be defined as a full time graduate student who was accepted in a master's program in social work and enrolled, but failed to graduate. Since the survey was designed to gather data on students leaving schools of social work, students who transferred to another school of social work were not considered. Also, part time students were excluded from the survey. The total dropout population was 662 students. This represents the total returned questionnaires from 29 schools covering the 3 year study period. The following. table presents the total dropout population broken down by year. 
Total Dropouts By Year

With and Without

Non-Accredited Schools

With non-acc. schools

N Percent of total

$1970^{*}$

1971

1972

$\underline{N} / \mathrm{R}$

TOTAL

\begin{abstract}
140
\end{abstract}
237

282

42.6

0.4

100

Without non-acc. schools

N Percent of total

$\begin{array}{ll}126 & 19.7\end{array}$

233

36.3

282

44

*1970 figure includes first year dropouts only

Table III includes four non-accredited schools in 1970 and two non-accredited schools in 1971. These non-accredited schools will be presented only in tables where no comparisons are made with the corresponding enrolled student population. The annual Statistics on Social Work Education list only accredited schools and by not withdrawing the non-accredited school's data, drop percentages would be misleadingly inflated.

The reader should be reminded of two additional points. First, the following tables present only data on full time students. Part time students will not be listed and are beyond the scope of this project. Second, 1970 findings encompass only first year students. This fact must be taken into consideration, as. first year rates are higher than 
combined first and second rates.

TABLE IV

Total Dropouts and Enrolled by Year

Excluding non-accredited Schools

Dropouts

N Percent of Total

$1970 * \quad 126 \quad 19.7$

$1971 \quad 233 \quad 36.3$

$1972 \quad 282 \quad 44$

TOTAL

$641 \quad 100 \%$
Enrolled

N $\quad$ Percent of Total

2,232

19.2

4,596

39.5

4,819

41. 4

$11,647 \quad 100 \%$

*1970 includes first year only

The data provided in Table IV shows the various percentages that each year represents of the total populations, both in dropouts and enrolled. The proportion of 1972 dropouts, when compared to the total number of dropouts, was higher than the proportion of 1972 enrollees when compared to the total enrolled population. This difference becomes even more apparant in comparing the percent increase in each of the populations. It was found that the total 1972 enrolled population had a 11.9 per cent increase over 1971, while the dropout population displayed a 21 percent increase for the same period. This shows that between 1971 and 1972 the dropout rate increased four times greater than the corresponding 
increase in the enrollment rate.

Before further examining findings on dropouts, the frequency and range of individual schools' drop rates should be explored.

The mean drop rate for twenty-five accredited schools in 1970 was 5.9 percent, with a standard deviation of 5.2. The rates for dropouts ranged from a low of no dropouts in one school to a high of 21.2 percent. Of the 25 schools responding in $1970,68.3$ percent had drop rates of 11 percent or less.

In 1971 the mean drop rate for 27 responding schools was 5.1 percent with a standard deviation of 3.6. The drop rate varied from a low of . 6 percent to a high of 15.1 percent, with a range of 14.5 percent. Also, 97.7 percent of all drop rates were 12.5 percent or lower.

The 1972 mean drop rate for 29 schools had increased to 6.3 percent with a standard deviation of 5.35. The distribution of the drop rate ranged from a low of no dropouts in one school to a high of 22.9 percent. In the 1972 sample population, 68.7 percent of the schools had a drop rate of 11 percent or less. A complete frequency distribution for all responding schools is listed in Appendix A. Data is presented for each school from 1970 to 1972 and lists the number enrolled, the number of dropouts, and the drop rate. 


\section{TABLE V}

Dropout Rates by Year

$\begin{array}{ll}1970 * & \text { N/A } \\ 1971 & 5.1 \% \\ 1972 & 5.9 \%\end{array}$

* 1970 includes first year only

The dropout rates presented in Table $V$ were arrived at by dividing the dropout population by the enrolled population for each year. These figures tend to misrepresent the ratio of enrolled to dropped if class year is not taken into account. When factoring by first and second year students a more accurate picture is given. Tables VI - X will bring this into proper perspective.

\section{TABLE VI}

Comparison of Total Enrollment and Dropouts by Class Year

Enrolled Percent of Enrolled Dropped Percent of Dropped

\begin{tabular}{lllll} 
First yr. & 7017 & 60.2 & 560 & 87.3 \\
Second yr. & 4630 & 39.8 & 75 & 11.7 \\
No Response & -- & -- & 6 & .9 \\
\cline { 2 - 2 } TOTA & 11,647 & $100 \%$ & 641 & $100 \%$
\end{tabular}

As can be seen, second year students represent only a small percentage of the total drop population. First year dropouts account for 87.3 percent of all dropouts reported, while second year dropouts only comprise 
11. 7 percent of the drop population.

Table VII presents the yearly rate of dropouts from Table V, broken out by class. It further clarifies the differences between first and second year dropout rates.

\section{TABLE VII}

Dropout Rates, by Year and Class

\begin{tabular}{|c|c|c|c|}
\hline Year & Total Drop Rate & First Year Rate & Second Year Rate \\
\hline 1970 & -- & $2.8 \%$ & -- \\
\hline 1971 & $5.1 \%$ & $4.1 \%$ & $.9 \%$ \\
\hline 1972 & $5.9 \%$ & $5.1 \%$ & $.7 \%$ \\
\hline
\end{tabular}

The first and second year drop rates were found by dividing, separately, the number of first and second year drops by the combined first and second year enrollments. Total percent figures were obtained by adding the first and second year drop rate in each year. This data shows the relationship of first and second year dropouts to the combined enrollment (lst and second year classes) for each year.

This table presents two significant findings. First, the combined first and second year drop rate increased from 1971 to 1972. Secondly, this rate increase is a direct result of the increase in first year dropouts. As canbe seen in Table VII, the second year drop rate has decreased by .2 percent from 1971 to 1972 . The 1971 second year dropout rate was 4.5 times smaller than the first year rate, while the 1972 second year drop rate was 7.3 times smaller than the corresponding 
first year rate.

The findings presented in Table VII must not be confused with those presented in Tables VIII, IX, and X. These tables are based on a comparison of first year dropouts to first year enrollments only and second year dropouts to second year enrollments only. In Table VII the first and second year dropouts were individually compared to combined first and second year enrollments.

The following tables, VIII, IX, and X, present a breakdown of first and second year students by the years 1970, 1971, and 1972. A comparison will be made exploring the ratios of the yearly enrolled and dropped populations when factored by first and second class years.

\section{TABLE VIII}

Comparison of Enrolled and Dropouts By Class in 1970 Enrolled Dropped Out N Percent of Total N

\begin{tabular}{|c|c|c|c|}
\hline First yr. & 2232 & 50.4 & 124 \\
\hline Second yr. & 2200 & 49.6 & N/A \\
\hline $\mathrm{N} / \mathrm{R}$ & $\ldots$ & $\ldots$ & 2 \\
\hline TOTAL & 4432 & $100 \%$ & $126^{*}$ \\
\hline
\end{tabular}

* In 1970 only first year dropouts are presented.

In 1970 the first year class comprised 50.4 percent of the total 1970 enrolled population. Since our survey only compiled data on the first year dropouts in 1970 , no comparison can be made between the ratio 
of first and second year drops. However, we do know that first year students in 1970 dropped out at a rate of 5.6 per 100 first year enrollees (5. 6\%). In 1971 and 1972 the relatively high frequency of first year dropouts can be more accurately portrayed.

\section{TABLE IX}

Comparison on Enrolled and Dropouts by Class in 1971

Enrolled

First yr.

$\underline{N} \quad \underline{\text { Percent }} \quad \underline{\text { Percent }}$

49

Percent

Dropouts

51

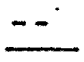

$100 \%$

190

81.5

Second yr.

2347

$\mathrm{N} / \mathrm{R}$

TOTAL . 4596
40

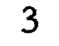

233
17.2

1.2

$100 \%$

In 1971, 27 accredited schools reported 233 dropouts. The first year class accounted for 49 percent of those enrolled, while first year dropouts accounted for 81.5 percent of dropouts. The second year class, possessing 51 percent of the enrolled population, accounted for 17.2 percent of dropouts. It becomes evident when factoring dropouts by class year shows that first year students drop at a much higher frequency than second year counterparts.

When comparing first year dropouts with first year enrollments it was found that first year students dropped out at a rate of 8.4 percent. In comparing second year dropouts with second year enrollment, a 1.7 
percent dropout rate was observed. The first year dropout rate was

3. 9 times larger than the corresponding second year drop rate, while both the first and second year group's enrollment were roughly 50 percent of the total population. Put another way, 8.4 first year students dropped out for every 100 who enrolled in 1971. Only 1.7 second year students dropped out for every 100 who enrolled in 1971.

The comparison between 1970 and 1971 first year drop out rates (5. $6 \%$ in 1970 and $8.4 \%$ in 1971 ), showed a 2.8 percent increase for that period. The 1971 second year dropout rate cannot be compared with 1970 figures since no data was collected in 1970 for second year students. The first year dropout rate continued to increase in 1972 as will be shown in the next table.

\section{TABLE $X$}

Comparison of Enrolled and Dropouts by Class in 1972

Enrolled

N $\quad$ Percent

Dropouts

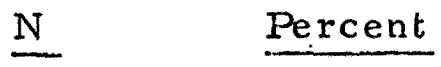

First yr.

52.6

246

87.2

Second yr.

2283

47.4

$\mathrm{N} / \mathrm{R}$

TOTAL 4819

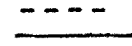

$100 \%$.
35

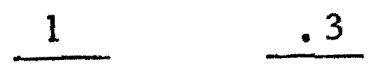

282
12.4

$100 \%$

In 1972 the 29 schools reported 282 dropouts. The first year class accounted for 52.6 percent of those enrolled and also contained 87.2 percent of all 1972 drops. The second year class, possessing 47.4 percent of 
those enrolled, contained only 12.4 percent of all $1972 \mathrm{drops}$.

When comparing first year dropouts and first year enrollments, it was found that first year students dropped at a rate of 9.7 percent. The comparison between 1972 second year dropouts and the second year enrollments showed a dropout rate of only 1.5 percent. The 1972 first year dropout rate was 5.5 times larger than the corresponding second year dropout rate. Thus, 9.7 first year students dropped out for every 100 who enrolled, while only 1.7 second year students dropped out for every 100 second year students enrolled in 1972 .

From the analysis of data gathered, it appeared that a trend existed in the first year student dropout rate. That rate was found to have increased each year from 1970 through 1972. As in 1971, the 1972 first year drop rate increased. The 1972 rate increase was found to be 1.3 percent higher than the preceeding year. For three years the following sequential increase was found in the first year drop rates: from 1970 to 1971 the rate increased 2.8 percent, from 1971 to 1972 the rate increased 1. 3 percent. No explanation is offered for this rate increase as it is not within the scope of this report.

No such trend was observed in the second year drop rates for the years studied. In fact the 1972 rate diminished by 2 per cent (from 1. $7 \%$ in 1971 to $1.5 \%$ in 1972). Further studies would be necessary to determine whether or not the rate of second year dropouts was in fact decreasing. 
The comparisons by class year pointed out the wide disparity batween first and second year student dropout rates. However, when factoring the variable of sex, there is no great difference between the dropout and enrolled populations. The following four tables present data on males and $f$ emales both for the dropped population and corresponding enrolled figures.

\section{TABLE XI}

Comparison of Total Dropouts and Enrolled by Sex*

\begin{tabular}{|c|c|c|c|c|}
\hline \multicolumn{2}{|c|}{ Dropouts } & \multirow[b]{2}{*}{ Percent } & \multicolumn{2}{|c|}{ Enrolled } \\
\hline & $\mathrm{N}$ & & $\mathrm{N}$ & Percent \\
\hline Male & 270 & 40.9 & 4665 & 40.3 \\
\hline Female & 379 & 57.3 & 6923 & 59.7 \\
\hline$N / R$ & 12 & 1.8 & $\cdots-$ & $\cdots-$ \\
\hline TOTAL & 661 & $100 \%$ & 11,588 & $100 \%$ \\
\hline
\end{tabular}

*Table XI excludes dropout and enrolled students from one school in 1970 which did not report sex breakdown.

The ratio of male to female holds fairly constant in both the dropout and enrolled population with females accounting for only 2.4 percent more in enrolled than in dropped. When comparing male and female dropouts to the corresponding enrollment figure, the frequency for females is 0.3 percent less than that for males ( 5.8 out of 100 males drop out and 5.5 out of 100 females drop out). This figure which controls the difference in size shows that while $f$ emales account 
for a greater proportion of both the enrolled and dropped populations; they drop out slightly less frequently than do males.

TABLE XII

Comparison of Dropouts and Enrolled by Sex in 1970\%

Dropouts $* * *$

N Percent

Male $\quad 50$

Female 72

$\mathrm{N} / \mathrm{R}$

3

TOTAL 125
40

57.6

2.4

$100 \%$

$\frac{\text { Enrolled** }}{\mathrm{N} \quad \text { Percent }}$

$874 \quad 40.2$

$1299 \quad 59.8$

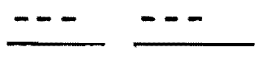

$2,173100 \%$

*1970 figures include first year only.

**Excludes one school which did not report a sex breakdown.

Table XII findings remain consistent with the total findings on sex. Females again represent a larger percentage in both populations. When comparing male and female dropouts with their respective enrolled populations, the female frequency is 0.2 less per 100 enrolled than males. In other words, the difference in dropout rates between sexes is insignificant when controlled for size. In 1970 males dropped out at a rate of 5.7 per 100 males enrolled and females at a rate of 5.5 per 100 females enrolled.

TABLE XIII

Comparison of Dropouts and Enrolled by Sex in 1971

\section{Dropouts}

N

Male $\quad 107$

Fe'male 122

$\mathrm{N} / \mathrm{R}$

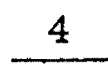

1. 7

Totals 233

45.9

52. 4
Percent

$2727 \quad 59.3$

Enrolled

N Percent

$1869 \quad 40.7$

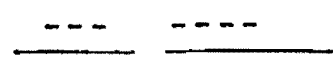

$4596 \quad 100 \%$ 
Table XIII shows the proportion of male dropouts in 1971 to be 5. 9 percent higher than the 1970 figures. However when size is controlled in comparison of male and f emale dropouts with their respective enrolled counterparts, Females show a slight decrease. Males dropped out at a rate of 5.7 per 100 enrolled, while females dropped out at a rate of 4.4 per 100 enrolled. It must be remembered here that the 1970 figures are for first year only, which may account for some of the difference.

TABLE XIV

Comparison of Dropouts and Enrolled by Sex in 1972

Dropouts

N P ercent of total

Male $\quad 113 \quad 40.1$

Female

$165 \quad 58.5$

$\mathrm{N} / \mathrm{R} \quad 4 \quad 1.4$

TOTAL

$282 \quad 100 \%$
Enrolled

N P 2 rcent of total

$1922 \quad 39.9$

$2897 \quad 60.1$

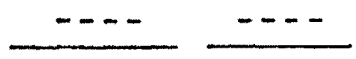

$4819 \quad 100 \%$

Comparing 1972 figures to 1971, the proportion of male dropouts

decreased by 5.8 percent while $f$ emales increased by 6.1 percent. When size is controlled we again find a very small difference between male and female dropout rates. 5.7 out of 100 males and 5.7 out of 100 f emales dropped out. 


\section{TABLE XV}

$1970 \quad \underline{1971} \quad \underline{1972}$ Total

$\begin{array}{lllll}\text { Male } & 2.3 \% & 2.3 \% & 2.3 \% & 2.3 \%\end{array}$

$\begin{array}{lllll}\text { Female } & 3.3 \% & 2.7 \% & 3.4 \% & 3.3 \%\end{array}$

Table XV graphically represents the male and female dropout rates whem compared to their corresponding total enrollment figures. Males consistently maintain a 2.3 proportion while females fluctuate from 2. 7 to 3.4. These findings again point out the small difference between male and Emale dropout rates (1.1\% of less). These figures are slightly misleading in that they show females with a slightly higher dropout rate. This happens due to the greater number of females in the population. However the previous tables have actually shown that females drop out at a slightly lower rate than do males when size is statistically controlled.

The preceding five tables indicate that females consistently account for approximately 60 percent of both the enrolled and dropout populations while males accounted for 40 percent. 1971 was an exception to this as male dropouts accounted for 45.9 percent.

The following tables XVI through XIX will present survey data on the age variable of dropouts. The age categories used are identical to those in CSWE statistics to allow comparison od dropouts to total enrollment. Table XVI compares combined total dropouts for 1971 and 1972 with the enrolled population for those same years. Table XVII shows the 
age breakdown of dropouts for 1970 only. Comparison with CSWE statistics is not possible as we have only first year dropout data for that year. CSWE statistics did not distinguish between 1 st and 2 nd year in age breakdowns in 1970. Table XVIII gives the age breakdown of dropouts for 1971 and a comparison with enrollment figures. Table XIXprovides similar data for 1972 .

Each table consists of five data columns -

Column 1- Age breakdown of dropouts

Column 2- Percent of dropout in each age category

Column 3- Percent of total enrolled population dropping out in each age category

Column 4- Age breakdown of total enrollment

Column 5- Percent of enrolled in each age eategory

\section{TABLE XVI}

Age Breakdown and Comparison of Dropout and Enrolled Populations in 1971 and 1972

\begin{tabular}{lcccccc}
\hline AGE & 1 & 2 & 3 & 4 & 5 \\
\hline Dropouts & $\begin{array}{c}\text { \% of total } \\
\text { Dropouts }\end{array}$ & $\begin{array}{c}\text { Dropout \% of } \\
\text { Enrollment }\end{array}$ & Total & Enrolled & $\begin{array}{c}\text { Percent of Total } \\
\text { Enrollment }\end{array}$ \\
$26-30$ & 285 & 55.3 & 3.0 & 4304 & 45.7 \\
$31-35$ & 119 & 23.1 & 1.3 & 2684 & 28.5 \\
$36-40$ & 41 & 8.0 & .4 & 987 & 10.5 \\
$41-45$ & 26 & 5.0 & .3 & 599 & 6.4 \\
46 \& over & 18 & 3.5 & .2 & 428 & 4.5 \\
NR & 15 & 2.9 & .2 & 287 & 3.0 \\
TOTAL & 11 & 2.1 & .1 & 126 & 1.3 \\
\hline
\end{tabular}


Table XVI shows that for the years indicated, the largest number of both enrolled and dropout students were 25 and Under. Also, the number of students in both the dropout and enrolled populations diminished as age increased.

More specifically, a 9.6 percent difference was noted between the proportion of dropouts and enrollees for the 25 and under age group. In other words, 55.3 of every 100 dropouts were under age 26 while only 45.7 of every 100 enrollees were under age 26 . In contrast, the proportion of dropouts in all other age categories was slightly less than their corresponding enrolled proportions. The lowest of these was the 26-30 age group which showed a difference of 5.4 percent (23.1\% of dropouts and $28.5 \%$ of enrollees.) It should be noted that 78.4 percent of all dropouts are age 30 or under.

TABLE XVII

Age Breakdown of Dropouts in 1970

\begin{tabular}{lccccc} 
& 1 & 2 & 3 & 4 & 5 \\
\hline AGE & Dropouts & $\begin{array}{l}\text { \% of total } \\
\text { dropouts }\end{array}$ & $\begin{array}{l}\text { Dropout \% of total } \\
\text { enrollment }\end{array}$ & N/A & N/A \\
\hline
\end{tabular}

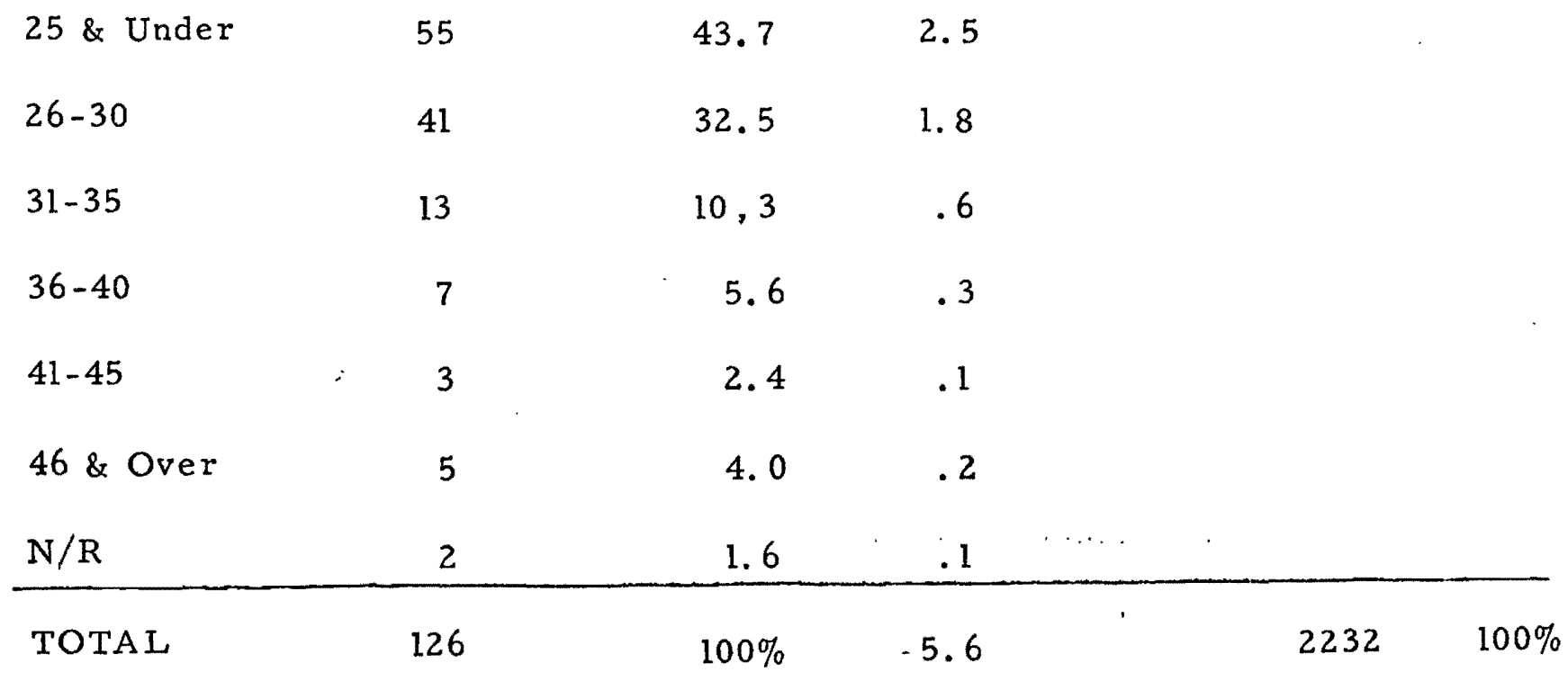


As mentioned earlier, it was not possible to make comparisons with the enrolled population in Table XVII, However, the dropout statistics show a high degree of consistency with those in Tables XVI, XVII, and XIX. The highest number of dropouts occurred in the 25 and Under age group. The number of dropouts in the other categories diminished as age increased with the exception of these students 46 and over. However, the number of these students was too small to be significant.

\section{TABLE XVIII}

Age Breakdown and Comparison of Dropouts and Enrolled Population in 1971

\begin{tabular}{lccccc} 
& 1 & 2 & 3 & 4 & 5 \\
\hline AGE & Dropouts & $\begin{array}{l}\text { \% of Total } \\
\text { Dropouts }\end{array}$ & $\begin{array}{l}\text { Dropout \% of } \\
\text { Total Enroll }- \\
\text { ment }\end{array}$ & $\begin{array}{c}\text { Enrolled } \\
\text { E of Total } \\
\text { Enrolled }\end{array}$ \\
\hline 25 \& Under & 123 & 52.8 & 2.7 & 1945 & 42.3 \\
$26-30$ & 56 & 24.0 & 1.2 & 1323 & 28.8 \\
$31-35$ & 21 & 9.0 & .5 & 499 & 10.9 \\
$36-40$ & 17 & 7.3 & .4 & 322 & 7.0 \\
$41-45$ & 7 & 3.0 & .2 & 220 & 4.8 \\
$46 \&$ Over & 5 & 2.1 & .1 & 161 & 3.5 \\
N/R & 4 & 1.7 & .1 & 126 & 2.7 \\
\hline Total & 233 & $100.0 \%$ & 5.1 & 4596 & $100 \%$
\end{tabular}




\section{TABLE XIX}

Age Breakdown and Comparison of Dropouts and Enrolled Population in 1972

\begin{tabular}{|c|c|c|c|c|c|}
\hline & 1 & 2 & 3 & 4 & 5 \\
\hline$\overline{\mathrm{AGE}}$ & Dropouts & $\begin{array}{l}\% \text { of Total } \\
\text { Dropouts }\end{array}$ & $\begin{array}{l}\text { Dropout \% of Total } \\
\text { Enrollment }\end{array}$ & Enrolled & $\begin{array}{l}\% \text { of Total } \\
\text { Enrolled }\end{array}$ \\
\hline 25 \& Under & 162 & 57.4 & 3.4 & 2359 & 49.0 \\
\hline $26-30$ & 63 & 22.3 & 1.4 & 1361 & 28.2 \\
\hline $3 l-35$ & 20 & 7. & .4 & 488 & 10.1 \\
\hline $36-40$ & 9 & 3.2 & .2 & 277 & 5.7 \\
\hline $41-45$ & 11 & 3.9 & .2 & 208 & 4.3 \\
\hline 46 \& Over & 10 & 3.5 & .2 & 126 & $\because 2.6$ \\
\hline$N / R$ & 7 & 2.5 & .1 & $\cdots$ & $\cdots$ \\
\hline Totals & 282 & $100 \%$ & 5.9 & 4819 & $100 \%$ \\
\hline
\end{tabular}

Tables XVIII and show a high degree of sim larity and consistency. Again the 25 and Under age group contained the highest frequency of dropouts. The proportion of dropouts in this category is 10.5 percent higher in 1971 and 8.4 percent higher in 1972 than the corresponding enrollment for this age group. Also, for both years the 26-30 age category contained the second highest frequency of dropouts and enrolled students. However, again in both years, this category has the lowest dropout proportion compared to its enrolled population (4.4\% lower in 1971 and $5.9 \%$ lower in 1972.) With few exceptions, the number of dropped and enrolled students declines with a scending age. The exceptions occur in the last three age categories 
with insignificant frequencies.

When examining the data for trends we compared the dropouts in the first three age categories ( 35 and Under) with their corresponding enrolled populations. This was possible only for the years 1971 and 1972. The first three categories were selected as they represent from 83 to 87 percent of all dropouts in those years.

We found that the 25 and Under age category exhibited a slight increase in dropouts from 1971 to 1972 . In 1971, out of every 100 enrolled students, 6.1 dropped out. In 1972, 6.9 out of every 100 dropped. A slight increase was also noted in the 26 to 30 age bracket. In 1971, 4. 2 out of every 100 enrollees dropped while 4.6 out of every 100 enrollees dropped in 1972. The 31-35 age group showed a minimal decrease from 4.2 per 100 in 1971 to 4.1 per 100 in 1972.

The above figures show that the observed trends are not a function of increased enrollment in those age categories. By statistically controlling for population fluctuations, it may be said that trends are developing for an increase in the ratio of dropouts in both of the 30 and Under age categories. A corresponding decrease in the ratio of dropouts in the 31 to 35 age category was noted. 
Ethnic Characteristics of Dropouts $1970-1972$

\begin{tabular}{lccc} 
& $\mathrm{N}$ & & Percent of Dropouts \\
\cline { 2 - 2 } White & 400 & 60.4 \\
Black & 93 & 14.1 \\
Chicano & 24 & 3.6 \\
Puerto Rico & 105 & 15.9 \\
American Indian & 11 & 1.7 \\
A sian American & 12 & 1.8 \\
Other U.S. & 0 & .0 \\
Foreign & 11 & 1.7 \\
N/R & 6 & .9 \\
\hline
\end{tabular}

Of the eight ethnic catagories studied, four contained the preponderance of dropouts. From 1970 through 1972 Whites, Blacks, Chicanos, and Puerto Ricans accounted for 94 percent of the drop population. Table $\mathrm{XX}$ gives the ethnic breakdown for all drop respondents but cannot be used for comparisons with CSWE data since several non-accredited schools were included in the totals. Table XXI presents the same breakdown as Table XX, except the non-accredited school figures have been 
removed for comparisons with CSWE.

TABLE XXI

Ethnic Characteristics of Enrolled Students and Dropouts from CSWE Accredited Schools, $1970-1972$.

$$
\begin{aligned}
& \text { Enrolled } \\
& \mathrm{N} \quad \text { Percent } \\
& \hline
\end{aligned}
$$

White

Black

Chicano

Puerto Rican

American Indian

A sian American

Other U.S.

Foreign

$\mathrm{N} / \mathrm{R}$

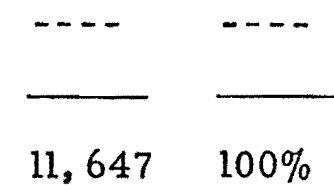

$1793 \quad 15.4$

432

3.8

546

4. 7

65

.6

201

1. 7

22

.2

267

2. 3
Dropped

N Percent

$92 \quad 14.4$

23

$3 ; 6$

$106 \quad 16.5$

15

2. 3

7

1. 1

. 00

12

1. 9

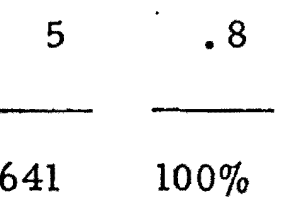

*Non-accredited schools removed from sample

The 1970-1972 totals show that white students account for 71.4 percent of the total enrolled population, while only comprising 59.4 percent of the drop population. From these figures it can be seen that the white student's drop rate was 12 percent less than their proportion of enrollment. There is only one other ethnic group that significantly 
varies in their rates of enrollment and dropping. Puerto Ricans, comprising only 4.7 percent of those students who enrolled, account for 16. 5 percent of those students who dropped. It should be noted that the University of Puerto Rico sent back data on 109 dropouts. Of these 109 drops, all but 4 were Puerto Ricans. This could skew the ethnic data as the University of Puerto Rico is located outside the continental United States and draws from a different population than the other schools of social work.

An ethnic breakout, factoring out the University of Puerto Rico's enrollm ent and drop populations can be found on page 71 of the appendix. Appendix B, Table I shows when the University of Puerto Rico's students are removed from the population, the ratio of enrolled to drop students remains relatively constant throughout all categories. In only one catagory does the ratio of dropouts increase significantly over those enrolled. While American Indians comprise only. 6 percent of those students enrolled from 1970 through 1972, they account for 2.8 percent of those who dropped out.

The following solution was devised in order to clarify the differences obtained when including the University of Puerto Rico in ethnic characteristics. The findings in Tables XXI through XXV can be used to represent data on all CSWE accredited schools.

Appendix $B$, Tables I and II can be used to represent trends and data for only those schools of social work located in the continental United States. This procedure allows both sets of data to be analysed 
while controlling for the possible skewing of data by the large frequency of Puerto Rico's dropouts.

The following Table presents data on enrolled students and dropouts in 1970 when factored by ethnic characteristics.

\section{TABLE XXII}

Ethnic Characteristics of Enrolled Students and Dropouts from 25 CSWE Accredited Schools in 1970.

$$
\begin{array}{ll}
\text { Enrolled } & \text { Dropped } \\
\text { N Percent } & \text { N Percent }
\end{array}
$$

White

$1610 \quad 72.1$

$75 \quad 59.5$

Black

$341 \quad 15.3$

15

11. 9

Chicano

$71 \quad 3.2$

$1 \quad .8$

Puerto Ŕican

$113 \quad 5.1$

$26 \quad 20.6$

A merican Indian

9.4

. 8

Asian American

40

1. 8

5

4. 0

Other U.S.

6.3

0

0

Foreign

42. $\quad 1.8$

1

.8

$\mathrm{N} / \mathrm{R}$

- $\quad-.$.

2

1.6

Total

$2232100 \%$

126

2



* Includes first year class only.

In 197072.1 out of every 100 students who enrolled were white, while only 59.5 out of every 100 who dropped out were white. This 
accounted for a 12.6 percent decrease in the enrolled to drop ratio. It must be remembered that the ratio will be much closer if the Univeristy of Puerto Rico is deleted from the sample, as in Appendix B Table 1 . The same will hold true for all other ratios in 1970. Also, the figures present first year students only and are skewed since second year data was not included.

The only other sizable difference found in 1970 was the ratio of Puerto Rican enrollees and dropouts. Puerto Ricans only accounted for 5.1 out of every 100 who enrolled while comprising 20.6 out of every 100 who dropped. This ratio becomes significant when comparing ethnicity in all CSWE schools responding. But, when viewing only those responding schools in the continental U.S., the enrolled to drop ratio is not significant. Again, data from Appendix B Table 1 supports this contention. 
Ethnic Characteristics of Enrolled Students and Dropouts from 27 CSWE Accredited Schools in 1971

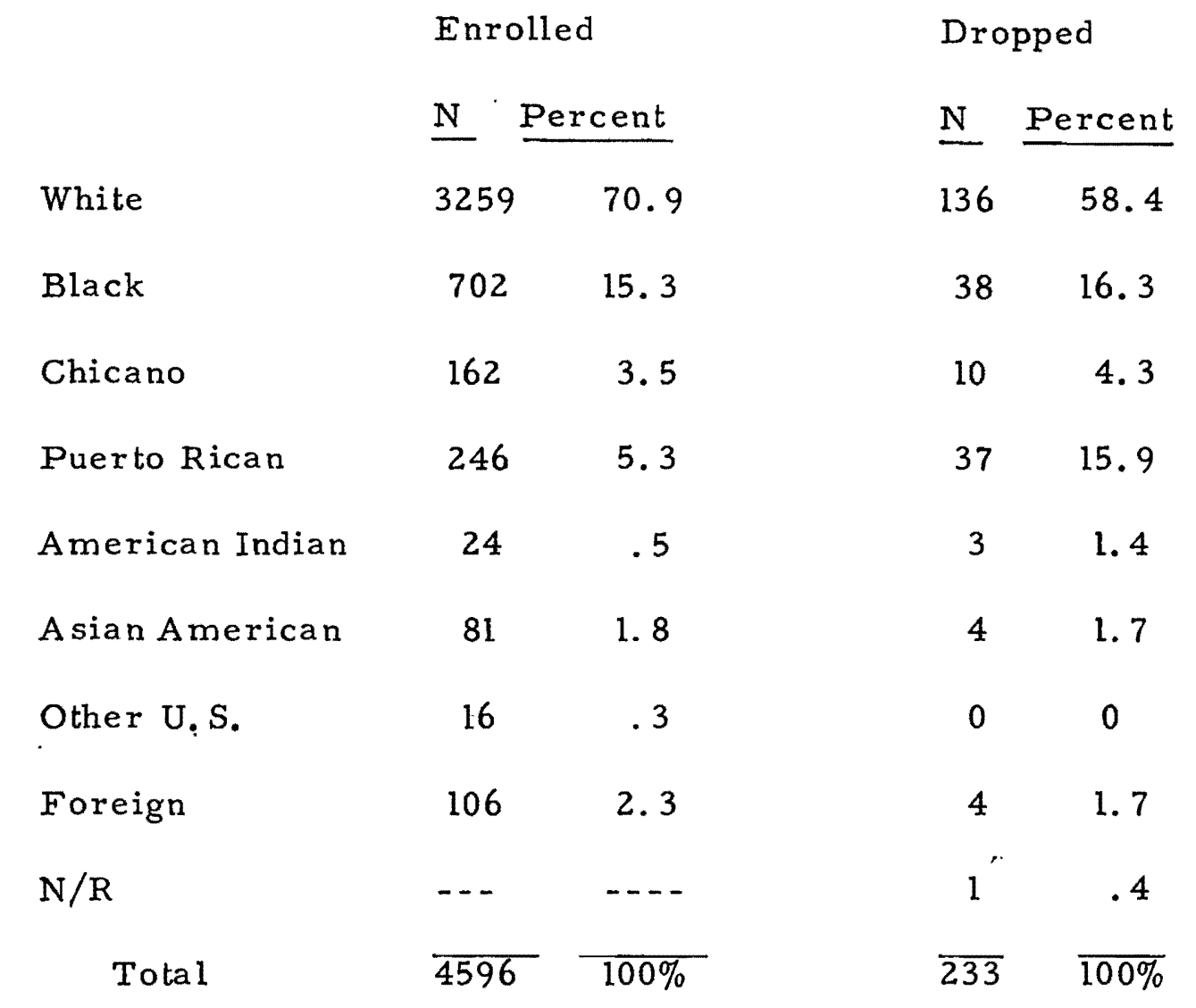

Table XXIII demonstrated that again in 1971 a large difference existed in the ratio of enrolled to dropouts for Whites and Puerto Ricans. White students comprised 70.9 out of every 100 who enrolled while only constituting 58.4 out of every 100 students who dropped out. Puerto Ricans made up 5.3 of every 100 who enrolled but accounted for 15.9 out of every 100 who dropped out. These differences are accounted for by the sizable number of Puerto Rican dropouts. When factoring dut the 
University of Puerto Rico, the ratio of both White and Puerto Rican enrolled students to dropouts becomes relatively insignificant. In all other ethnic categories only a one percent or less difference was noted.

\section{TABLE XXIV}

Ethnic Characteristics of Enrolled Students and Dropouts from 29 CSWE Accredited Schools

in 1972

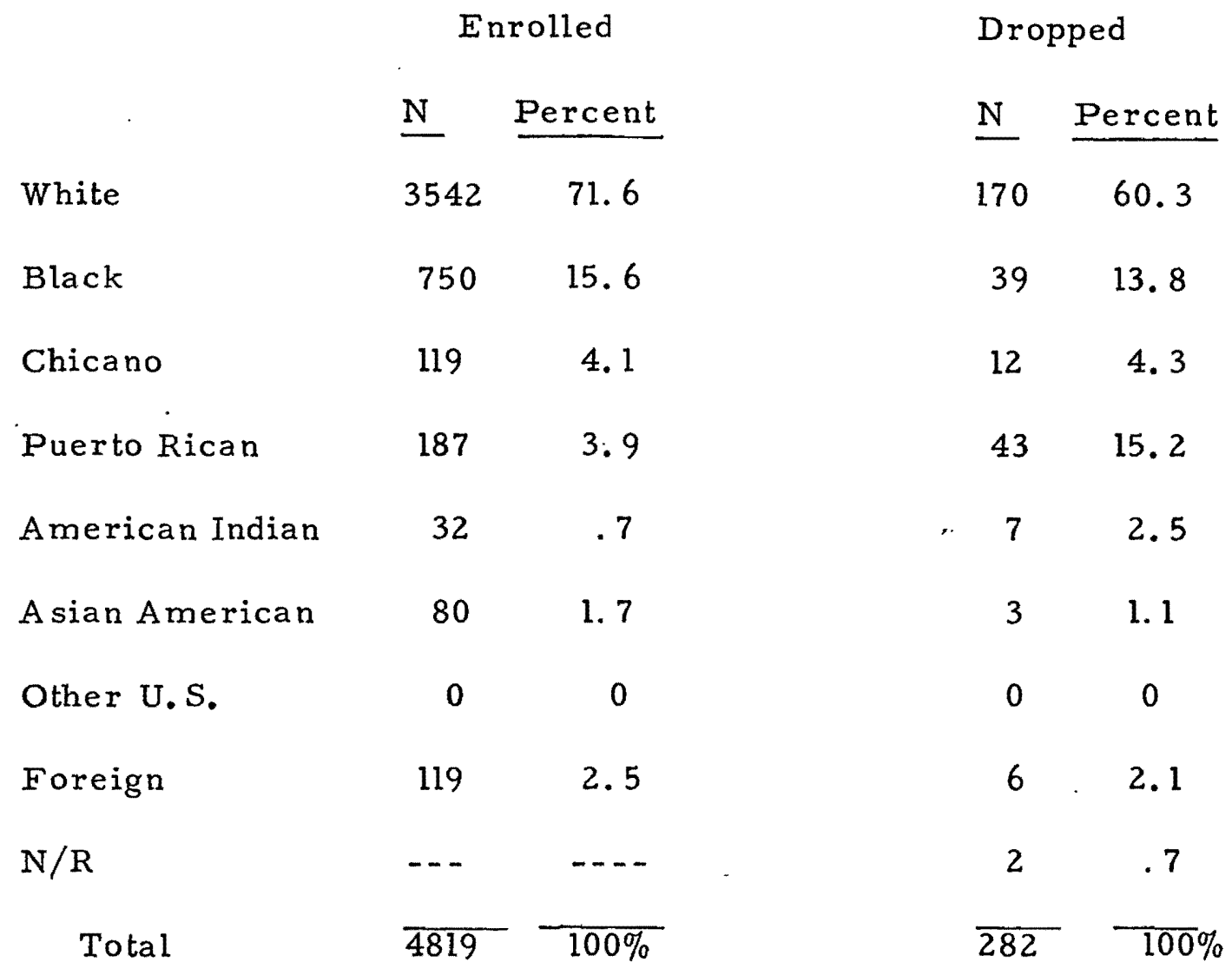

A nother means to examine the ethnic data gathered on dropouts was to determine what percentage of each ethnic group dropped out. This was achieved by dividing the number of dropouts in each ethnic group by the corresponding number of enrollments for that group. The 
following table presents these findings.

TABLE XXV

Percentages of Dropouts for Each Ethnic Catagory by year. 1970-1972.

$\begin{array}{lccc} & 1970 & \underline{1971} & 1972 \\ \text { White } & 4.7 \% & 4.2 \% & 4.8 \% \\ \text { Black } & 4.4 \% & 5.4 \% & 5.2 \% \\ \text { Chicano } & 1.4 \% & 6.2 \% & 10.1 \% \\ \text { Puerto Rican } & 23.0 \% & 15.0 \% & 23.0 \% \\ \text { American Indian } & 11.1 \% & 12.5 \% & 21.9 \% \\ \text { A sian American } & 12.5 \% & 4.9 \% & 3.8 \% \\ \text { Other U.S. } & 0 \% & 0 \% & 0.0 \% \\ \text { Foreign } & 2.4 \% & 3.8 \% & 5.0 \%\end{array}$

*Includes first year only - will inflate percentages - can only compare 1971-1972.

In 1970 data was only gathered on the first year class, thus a comparison cannot legitimately be made with 1970 and the other two years studied. The data will only be valid for the first year class.

In all but two ethnic groups had a drop rate of around 5 percent plus or minus 1 percent. Two other ethnic groups that exceeded the "normal" rate were Puerto Ricans and American Indians. In 1971, of those Puerto Ricans enrolling, 15 percent later dropped out. Also, 12.5 percent of the total American Indian enrollment dropped.

When comparing 1972 ethnic data with 1971, it was found that Puerto Ricans and American Indians again dropped out a greater than 5 percent rate. It was also noted that Chicano students had exceeded the 5 percent drop rate. 
In 1972 the Chicano dropout rates increased by 3.9 percent to 10.1 percent ( 1.6 times the 1971 rate). The Puerto Rican rate increased by 8 percent to 23 percent, also 1.6 times the 1971 rate. The American Indian rate displayed an even greater increase. It rose by 9. 4 percent to 21.9 percent ( 1.8 times the 1971 dropout rate).

The American Indian drop rate increased from 1971 to 1972 as their enrolled population also increased. What is more significant is the fact that both the Chicano and Puerto Rican enrollments decreased from 1971 totals, yet their dropout rate increased. This means that fewer Chicanos and Puerto Ricans enrolled in 1972 and their percentages of dropouts to enrolled students increased at an even higher ratio than in 1971. The 1971-1972 trends shows that certain ethnic groups are not remaining in school at levels comparable to other ethnic minorities. For example, the Black dropout rate decreased .2 percent of our sample population, from 5.4 percent in 1971 to 5.2 percent in 1972. While the Black enrollment rose by 48 students in 1972 , their drop rate decreased.

1972 figures indicated that the significant differences in enrolled to drop ratios occured in Whites and Puerto Ricans. In 1972 71.6 out of every 100 who enrolled were White while only constituting 60.3 out of every 100 dropouts. Puerto Ricans comprised 3.9 out of every 100 who enrolled and accounted for 15.2 out of every 100 who dropped out. It was also found that American Indians accounted for 
only .7 of every 100 who enrolled but made up over 2.5 of every 100 who dropped out. Of the three ethnic catagories where a ratio difference was noted, only the American Indian figures cannot be explained by the University of Puerto Rico's influence on the sample population.

The 1972 data for American Indians shows over a 250 percent increase in the ratio of those enrolled to those who dropped out. Though the actual number of American Indians who enrolled and dropped was small it is the only sizable increase in the comparison of drop and enrolled students rates in 1972. Coupled with the fact that graduate schools of Social Work are attempting to increase the number of minority graduates, this finding may take on a greater significance than its small population would normally merit. Observations will have to be made in succeeding years to see if this is the beginning of a trend.

Table XXVI presents the findings on dropouts who received some type of financial grant while in school in 1971 and 1972. In addition, there is a comparison of the dropouts with the enrolled population receiving grants for the same years. 


\section{TABLE XXVI}

Dropout and Enrolled Students Receiving Financial Grants in 1971 and 1972

$$
\text { Dropouts }
$$

1971

With grants

N Percent

W/o grants

Unk.

$\mathrm{N} / \mathrm{R}$

1972

With grants

163

57.8

2975

61. 7

W/o grants

111

39.3

Unk

4

1. 4

$\mathrm{N} / \mathrm{R}$

4

Enrolled

N Percent

2805

61.0

38.6

4. 3

.9

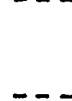

- -

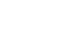


but cannot be safely interpreted as a trend.

For the following six variables on demographic data and reasons for dropping out, there is no corresponding data available in the CSWE statistics. Therefore we have once again included the dropout data from the non-accredited schools. In terms of raw numbers this means that there was a total of 29 schools returning information on a total of 662 dropouts. In the yearly breakdown the $\mathrm{N}$ will be 659 as 3 questionnaires were invalidated.

\section{TABLE XXVII}

\section{Marital Status of Dropouts - Total}

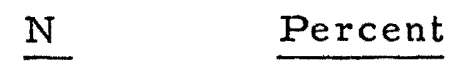

\begin{tabular}{lcc} 
Single & 354 & 53.5 \\
Married & 262 & 39.6 \\
Divorced & 27 & 4.1 \\
Widowed & 6 & 0.9 \\
Separated & 7 & 1.1 \\
Unknown & 6 & 1.9 \\
\multicolumn{1}{r}{ Total } & 662 & $100 \%$
\end{tabular}

Table XXVII shows that 53.3 percent or 354 persons of the total dropout population are single. Married dropouts comprised 39.6 percent or 262 individuals of the total population, while divorced accounted for only 4.1 percent ax 27 people. Widowed and separated dropouts had 
a very small portion of the total population with .9 and 1.1 percents respectively.

TABLE XXVIII

Marital Status of Dropouts, By Year

\begin{tabular}{ll}
$\frac{1970}{*}$ & 1971 \\
$\mathrm{~N}$ Percent & 1972 \\
\hline
\end{tabular}

Single

$73 \quad 52.1$

$\begin{array}{llll}122 & 51.5 & 158 & 56\end{array}$

Married

$58 \quad 48.4$

$94 \quad 39.7$

$109 \quad 38.7$

Divorced

$6 \quad 4.3$

13

5.5

$8 \quad 2.8$

Widowed

$1 \quad 0.7$

$3 \quad 1.3$

2

0.7

Separated

$1 \quad 0.7$

$3 \quad 1.3$

31.1

$\mathrm{N} / \mathrm{R}$

Total

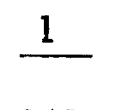

$\underline{0.7}$

$2 \quad 0.8$

$2 \quad 0.7$

140

$100 \% \quad 237 \quad 100 \%$

$282 \quad 100 \%$

* 1970 includes first year students only.

Table XXVIII illustrates the marital status of dropouts in each year of the study period. In general, these breakdowns remain consistent with the total findings. Single dropouts maintained between 51.5 and 65 percent of their respective year's total, with 1972 having the highest proportion (56\%). Married dropouts consistently held the next highest percentages in all three years. However there is some fluctuation within the yearly breakdowns. Notably, 1970 had approximately a 10 percent higher frequency of married dropouts than either 1971 or 1972. 
Divorced dropouts comprised the third largest category in all three years. Again there was a small variance in their percentage of the yearly totals. 1971 divorced dropouts were 1.2 percent greater than 1970 's and 2.7 percent more than 1972 's proportion. The categories of widowed, separated and unknown comprised the remainder of the total yearly percentages but had rather insignificant frequencies.

In summation there appear to be no observable trends within the yearly breakdowns. That is, none of the categories are either increasing or decreasing in a significant manner.

TABLE XXIX

\begin{tabular}{|c|c|c|}
\hline & $\underline{N}$ & Percent \\
\hline No children & 500 & 75.5 \\
\hline One & 54 & 8.2 \\
\hline Two & 41 & 6.2 \\
\hline Three or more & 44 & 6.6 \\
\hline No Response & 23 & 3.5 \\
\hline Total & 662 & $100 \%$ \\
\hline
\end{tabular}

The above table gives a breakdown of the total dropout population in terms of the number of their children that were living at home. As can be seen, the overwhelming majority, 75.5 percent, had no children at home. Dropouts with either one, two or three or more children at home represent a near equal distribution. One child at home occurred at 
approximately a 2 percent greater frequency than the other categories.

\section{TABLE XXX}

Family Size of Dropouts,

by Year

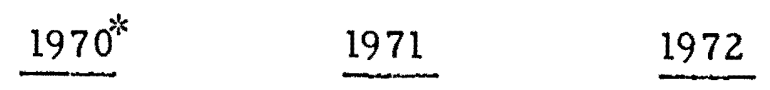

\section{N Percent $N$ Percent $N$ Percent}

No children

94

$67.1 \quad 175$

$73.8 \quad 221$

78.4

One

19

$13.6 \quad 17$

$7.2 \quad 26$

9.2

Two

I1

$7.9 \quad 18$

$7.6 \quad 12$

4. 3

Three or more

11

$7.9 \cdot 17$

$7.2 \quad 16$

$-5.7$

No Response

$\frac{5}{140} \quad \frac{7.9}{100 \%} \cdot \frac{10}{100 \% 282} \frac{4.2}{100 \%}$

Total

140

*Includes first yeat students only.

In general the yearly figures are compatible with those presented in the totals table. Dropouts with no children constitute the largest category by at least a 55 percent margin in all three years. Again as in the totals, dropouts with one child at home comprised the next highest frequency, followed by two then three children at home.

In comparing the across the years there appearsto be some notable trends. Specifically, there is approximately a 5 percent per year increase in the number of dropouts with no children. Correspondingly there is a slight decrease in the number of dropouts with 2,3 or more children. Those dropouts with one child at home presented an inconsistent picture but also appeared to be on the decrease. 
It's difficult to assess the significance of these trends because we had no information as to the characteristics of the total enrolled population. Therefore the variance between the years may simply be a function of changes in the total enrolled population and have little significance to identification of potential dropouts.

\section{TABLE XXXI}

Type of Concentration of Dropouts - Total

$\begin{array}{lcc} & \text { N } & \text { Percent } \\ \text { Generic } & 327 & 49.4 \\ \text { Casework } & 138 & 20.9 \\ \begin{array}{l}\text { Community organization } \\ \text { and Planning }\end{array} & 52 & 7.9 \\ \text { Group Work } & 27 & 4.1 \\ \text { Micro-Intervention } & 30 & 4.5 \\ \text { Other } & 39 & 5.9 \\ \text { No Response } & 49 & 7.4 \\ \quad \text { Total } & 662 & 100 \%\end{array}$

Table XXXI presents the total dropout population distribution according to their area of concentration within the graduate program. The academic track of "generic" social work accounted for almost 50 percent (49.4\%) of the total dropout population. The next highe'st frequency was "casework" with 20.9 percent. The remaining 30 percent of the total dropout population was distributed fairly equally among the remaining categories. Unfortunately this also includes the "no response" category with 7.4 percent of the total population. The areas of 
concentration were taken from Table 254 in Statistics on Graduate Social

Work Education in the United'States: 1972. The six categories comprised over 90 percent of all enrolled students.

TABLE XXXII

Type of Concentration of Dropouts, By Year

\begin{tabular}{|c|c|c|c|c|c|}
\hline 197 & & 197 & & 19 & \\
\hline $\mathrm{N}$ & Percent & $\mathrm{N}$ & Percent & $\mathrm{N}$ & Percent \\
\hline 55 & 39.3 & 109 & 46 & 162 & 57.4 \\
\hline
\end{tabular}

Generic

$43 \quad 30.7$

56

23.6

$39 \quad 13.8$

Community Organization

$7 \quad 5$

21

8.923

8.2

and Planning

Group Work

96.4

9

3. 810

3.5

Micro Intervention

6

4.3

5

$2.1 \quad 18 \quad 6.4$

Other

8

5.7

14

5.916

5.7

No Response

$\frac{12}{140} \frac{8.6}{100 \%} \quad \frac{23}{237} \frac{9.7}{100 \%} \frac{14}{282} \frac{5.0}{100 \%}$

Total

*Includes first year students only.

In Table XXXII, which presents a yearly breakdown on the variable "Area of Concentration," the category of "generic" social work contains the highest proportion of dropouts in all three years. The percentage of dropouts in this category appears to be increasing as there is a 6.7 percent increase from 1970 to 1971 and an 11.4 percent incréase from 1971 to 1972. The next highest frequency of dropouts occurred in the academic 
track "casework" within each year of the study period. The trend within this category seems to be decreasing, roughly corresponding to the increases noted above. 1971 had 7.1 percent fewer dropouts in the casework track than 1970 and 1972 had 9.8 percent fewer than did 1971.

The only other category with any consistent trend is that of "Group work." Here there appeared to be a slight decrease in dropouts over the study period. However this category represented only 6.4 percent of the population in $1970,3.8$ percent in 1971 and 3.5 percent in 1972 . The remaining categories of "Community Organization and Planning", "MicroIntervention" and "Other" comprised a small percentage of the total yearly populations. In addition, there appeared to be no consistent trends, with the exception of "Other".which remained near 6 percent in all three years.

The assessment of the significance of the trends is once again hampered by the lack of comparitive data. An additional constraint placed on these particular interpretations is the relatively high frequency of "No Response" within each year period. (8.6 percent in 1970, 9.7 percent for 1971 and 5 percent in 1972.)

\section{TABLE XXXIII}

Previous Social Work Experience of Dropouts - Totals

$$
1 \quad \text { Percent }
$$

With experience $286 \quad 43.2$

W/out experience

$349 \quad 52.7$

Unknown

$$
17 \quad 2.6
$$

No Response

$-\frac{10}{662} \frac{1.5}{100 \%}$


Table XXXIII presents the total figures on the variable "Previous Social Work Experience." This was defined as having at least one year's full time employment in the area of social services prior to entering graduate school. As can be seen, those dropouts without previous experience represented 9.5 percent more of the total population than did those dropouts with previous experience.

\section{TABLE XXXIV}

Previous Social Work Experience of Dropouts by Year

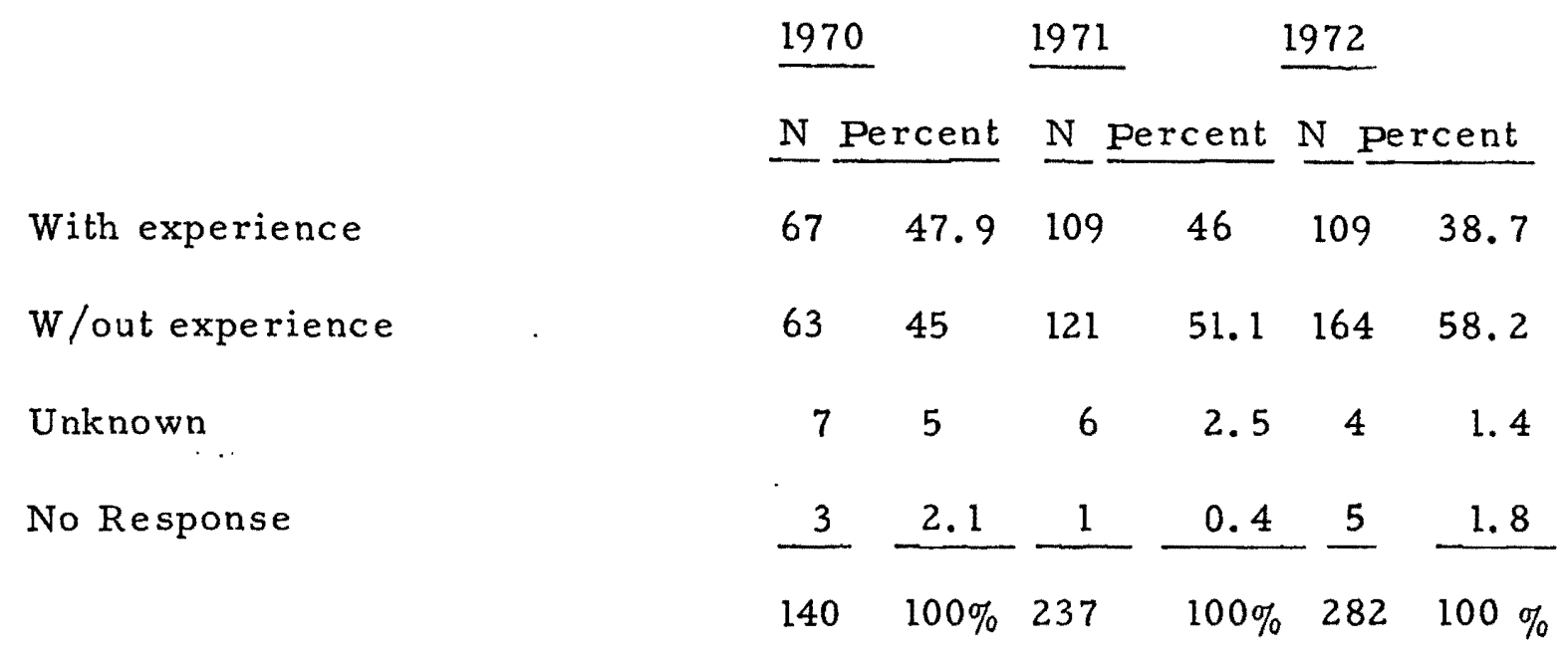

* 1970 includes first year students only.

The yearly totals show that 1970 is the only year in which dropouts with previous experience outnumbered those without. 1970 figures indicated that 2.9 percent more students with experience dropped out than those without. However in 1971 and 1972 the reverse held true. In 1971 there were 5.1 percent more dropouts without previous experience while in 1972 those without experience outweighed those with by 19.5 percent. 
When examining these categories across the years, a general increase was observed in dropouts without previous experience. A corresponding decrease was found in students dropping out with previous experience. This is particularly evident in 1971 and 1972 where the "no response" and "Unknown" categories contained a relatively low percentage. However here again it is difficult to evaluate the significance of these trends without comparable data from the total enrolled population.

Table XXXV presents the study findings on the employment of drop out students while in school. The range of categories is; not employed, employed under ten hours per week, 10 to 20 hours per week, over 20 hours per week and unknown.

\section{TABLE XXXV}

Employment Status of Dropouts

Employment status 1970\# 1971 1972 Total N Percent N Percent N Percent N Percent

Not employed $75 \quad 53.6$ $137 \quad 57.8$ 187 66.3 $403 \quad 60.9$

Under $10 \mathrm{hrs} / \mathrm{wk}$ $0 \quad 0$

.93 .1

3

1. 1

10

1.5

$10-20 \mathrm{hrs} / \mathrm{wk}$

64.3

3

1. 3

12

4. $3 \quad 21$

3.2

Over $20 \mathrm{hrs} / \mathrm{wk}$

$5 \quad 3.6$

3

1. 3

4

1. $4 \quad 12$

1. 8

Unknown

$49 \quad 35.0$

$78 \quad 32.9 \quad \therefore 68$

$24.1 \quad 195 \quad 29.5$

$\mathrm{N} / \mathrm{R}$ $5 \quad 3.6$

73

8

2.8 $21 \quad 3.2$

Total $140 \quad 100 \%$

$237 \quad 100 \%$

282

$100 \% \quad 662 * 100 \%$

\#1970 includes first year dropouts only

* Total (662) includes 3 student whose dropout year is unknown. 
As Table XXXIII indicates the great majority of dropout students were not employed. Also, the proportion of those not employed has increased significantly each year.

There is little consistency in the three hourly employed categories. The frequency of students in these categories is quite small. Over the three year period the highest proportion of employed dropouts were apparently working 10 to 20 hours per week.

The high rate of response in the unknown" category tends to severly limit the significance of data on this variable. Although the rate of unknown responses declined over the three years studied, it still averaged almost 30 percent. We can only speculate about the employment status of those in the unknown category. The significance of trends cannot be verified as there is no comparable data from the enrolled population. These trends may simply be the result of fluctuations in enrollment.

\section{TABLE XXXVI}

Residential Status of Dropouts - Totals

Resident of state

Non-resident

No Response

Total
N $\quad$ Percent

$470 \quad 71.0$

$171 \quad 25.8$

$21 \quad 3.2$

$662 \quad 100 \%$ 
TABLE XXXVII

Residential Status of Dropouts, By Year

\begin{tabular}{|c|c|c|c|c|c|}
\hline \multicolumn{2}{|r|}{$1970^{*}$} & \multicolumn{2}{|c|}{1971} & \multicolumn{2}{|c|}{1972} \\
\hline $\mathrm{N}$ & Percent & $\mathrm{N}$ & Percent & $\mathrm{N}$ & Percent \\
\hline 103 & 73.6 & 168 & 70.9 & 196 & 69.5 \\
\hline 33 & 23.6 & 55 & 23.2 & 83 & 29.4 \\
\hline 4 & 2.9 & 14 & 5.9 & 3 & 1.1 \\
\hline 140 & $100 \%$ & 237 & $100 \%$ & 282 & $100 \%$ \\
\hline
\end{tabular}

*1970 includes first year students only.

The above tables delineates the distribution of the dropouts in terms of residential status. Table XXXVI dipicts the total dropout population. Residents of the State in which the school is located comprise 71 . percent of the total population. This also holds true in Table XXXVII which presents the yearly totals. However if we utilize the ratio of residents to non-residents there appears to be some variance between the years. In 1970, the difference between residents and non-residents is 50 percent, in 1971 the ratio is 47.7 percent and in 1972 it is 40.1 percent. These figures would indicate a general decrease in the number of dropouts that are state residents. However, the rate of "no response" is high enough in 1970 (2.9 percent) and 1971 (5.9 percent) to account for these differences. Another unknown is the residential status of the total enrolled population. Along with the original questiomaires mailed out, was included a 
set of definitions for specific reasons for dropping out. Those definitions are as follows:

\section{Financial:}

Student chose or was forced to drop out due to financial pressure.

2. Personal:

Marital - Student dropped out due to stress resulting from dysfunction within the marital relationship.

Emotional Adjustment - Inability of student to resolve interpersonal or intra-personal conflicts and/or adjust to the pressures of graduate study resulting in discontinuation of the program.

Spouse Moved. - In the absence of serious marital problems the student discontinues program to accompany spouse on move necessitated by job transfer, health, etc.

Crisis - A sudden acute event; the impact or resolution of which necessitated the student dropping out of school (e.g. death in family).

3. Academic:

Failed Academically - Failure of student to maintain minimum G.P.A. or other standards set by school for course work. Failed in Field Practicum. - Failure of student to perform satisfactorily in field practicum.

Counseled Out - Student acted upon advice of school to discontinue due to impending failure or unsatisfactory performance. 
4. Health:

Student discontinued program due to physical health problems.

5. Pregnancy:

Females only.

Also included were the following possible reasons for dropping out which were not specifically defined as they are self explanatory. They are: (6) Dissatisfaction with the school's curriculum, (7) Dissatisfaction with the profession of Social Work, (8) Lack of future employment in Social Work, (9) Other reason and (10) Reason Unknown.

In the "Other reason" category we asked that respondents specify, if possible. There were three specific other reasons which were reported most often. These three, which are included in Table 38, are Marriage, Job and Death. Marriage meant the student dropped out to get married. Job meant the student dropped out to take employment.

Along with the definitions we included the following statement as a guideline for use with our definitions and as an aid in determining selection of the primary reason for dropping out.

"We are aware that there may be several interrelated factors involved in a student's decision to drop out of school. However, we ask that you select the ultimate or most significant reason as stated by the student or determined by the school rather than a precipitating event."

"The definitions offered here for the various reasons for dropping out are 
certainly open to interpretation. We offer them as a general guide and hope they will be used as such."

Table XXXVIII records the data on reasons given for dropping out.

TABLE XXXVIII

Reasons For Dropping Out

Reason For Dropping Out

1971

N Percent
Total

N Percent N Percent N Percent N Percent

$\begin{array}{lrrrrrrrr}\text { 1) Financial } & 14 & 10 & 32 & 13.5 & 35 & 12.4 & 81 & 12.2 \\ \text { 2) Personal (Tota1) } & 42 & 30 & 63 & 26.6 & 73 & 25.9 & 179 & 27 \\ \text { a) Marital } & 5 & 3.6 & 4 & 1.7 & 10 & 3.5 & 20 & 3 . \\ \text { b) Emotional Adj. } & 18 & 12.9 & 31 & 13.1 & 37 & 13.1 & 86 & 13 \\ \text { c) Spouse Moved } & 6 & 4.3 & 9 & 3.8 & 8 & 2.8 & 23 & 3.5 \\ \text { d) Crisis } & 6 & 4.3 & 5 & 2.1 & 7 & 3.2 & 20 & 3 . \\ \text { e) Other pers. } & 7 & 5 & 14 & 5.9 & 9 & 3.2 & 30 & 4.5\end{array}$

3) Academic (Total) 38

$\begin{array}{rrrrrrl}27.1 & 57 & 24.1 & 56 & 19.9 & 152 & 23 \\ 7.1 & 26 & 11 & 30 & 10.6 & 67 & 10.1 \\ 2.9 & 9 & 3.8 & 6 & 2.1 & 19 & 2.9 \\ 16.4 & 21 & 8.9 & 18 & 6.4 & 62 & 9.3 \\ .7 & 1 & .4 & 2 & .7 & 4 & .6\end{array}$

4) Health

64.3

9

3. $8 \quad 13$

$4.6 \quad 28$

4.2

5) Pregnancy

$2 \quad 1.4$

1.4

$\begin{array}{lll}2 & .7 & 4\end{array}$

8.3

6) Curriculum

$\begin{array}{lllllllll}\text { Dissatisfaction } & 1 & .7 & 11 & 4.6 & 16 & 5.7 & 28 & 4.2\end{array}$

7). Dissatisfaction $w /$
Profession
13
9.3
16
$6.8 \quad 25$
$8.9 \quad 55$
8.3

8) Lack of Future

Employment S. W.

9) Other (Total)
a) Marriage
b) Job
c) Death

$\begin{array}{rr}11 & 7.9 \\ 5 & 3.6 \\ 1 & .7 \\ 1 & .7\end{array}$

7.9

28

11.8

28

9.968

10.3

\section{.7}

.7

5

2.1

2.5

17

2. 5

6

2.5

2.1 14

2.1

6

2.5

3

1.110

1.5

10) Reason Unknown

139.3

20

8.4

32

11.8

65

9. 8

11) $N / R$

Total

\begin{tabular}{cc}
$\ldots$ & $\cdots$ \\
\hline 140 & 100
\end{tabular}

$-$

$\begin{array}{llll}2 & .7 & 2 & .3\end{array}$


There appears to be few consistent trends in "reasons for dropping out" within the study period. The highest number of dropouts for all years was attributed to "personal" reasons (2) with emotional adjustment (2b) being the largest specific personal reason. Emotional adjustment held fairly steady for all years while overall personal reasons have declined slightly but gradually. Spouse moved (2c) has shown a slight but gradual decline.

The second largest number of dropouts was accounted for by academic reasons (3). This catagory also has declined steadily for the three year period. Under academic reasons the proportion of students counseled out $(3 c)$ has decreased each year also. While the counseled out category accounted for the highest number of dropouts under academic reasons in 1970, Academic failure (3a) accounted for most of the dropouts in 1971 and 1972 under academic reasons.

The only other consistent trend in reasons for dropping out was the increase in curriculum dissatisfaction (6). Dropouts for this reason jumped 3.9 percent from 1970 to 1971 and again increased 1.1 percent from 1971 to 1972.

The remaining reasons for dropping out either increased or decreased at an inconsistent rate or remained fairly stable (within $1 \%$ ). In some categories numbers were too small to be significant. 


\section{SUMMARY AND CONCLUSIONS}

The focus of this study was to gather information on dropout students from graduate schools of Social Work throughout the nation. The information sought was in two major categories; demographic characteristics and reasons for dropping out. Questionnaires were sent to all accredited schools listed in the 1972 CSWE Statistics on Graduate Social Work Education in the United States. Of the 77 schools contacted, completed questionnaires were returned by 29 .

The survey population was those students who had dropped out their first year of graduate study in 1970, 1971 and 1972 and those who had dropped out of their second year in 1971 and 1972 .

The total number of dropouts from participating schools was 662 for the entire study period. As might be expected, first year dropouts far exceeded second year drops by a ratio of nearly 6 to 1 .

When broken down by Sex it was found that more f emales dropped out than males. However, when dropouts are compared with the enrolled population it was found that the proportion of $f$ emale drops was slightly lower (2. $4 \%$ ) than the proportion of $f$ emales enrolled. The proportion of male dropouts was slightly higher $(0.6 \%)$ than the proportion of males enrolled. Males dropped out at the rate of 5.8 per 100 males enrolled and $f$ emales at a rate of 5.5 per $100 \mathrm{f}$ emales enrolled.

When factored by age, over half $(55.3 \%)$ of the dropouts fell in the "25 and Under" age bracket. The proportion of dropouts in this age 
category was almost 10 percent higher than its corresponding enrolled population. As age increases the number of both enrollees and dropouts decreased. Also, the proportion of dropouts from all other age groups was lower than it's corresponding enrolled population.

The ethnic breakdown of dropouts shows that Whites comprise over half $(59.4 \%)$ of all dropouts. Puerto Ricans account for 16.5 . percent of the dropouts; Blacks, 14.4 percent, Chicanos 3.6 percent, American Indians 2.3 percent, A sian Americans 1.1 percent and foreign students, 1. 4 percent. However, when we compare the various ethnic dropouts to their corresponding enrolled populations we get a different perspective. The American Indian dropouts account for 23.1 percent of all American Indians enrolled, or 1 dropout for every 4.3 enrollees. In contrast, White dropouts account for only 4.6 percent of all enrolled Whites, or one dropout for every twenty-two enrollees. The ratio of dropouts to enrollees for the remaining ethnic groups is: Puerto Rican, 1 out of 5.1; Chicano, 1 out of 18.7; Black, 1 out of 19.4; Foreign, 1 out of 22.2 and A sian American, 1 out of 28.7. In examining yearly trends of dropouts by ethnicity, both American Indian and Chicano show marked increases from 1970 to 1972. Foreign students also show a gradual but less dramatic increase. White, Black and Puerto Rican show in consistent patterns. Asian American is the lone ethnic group showing a consistent decrease in dropouts.

For the years 1971 and 1972 the proportion of dropouts receiving financial grants averaged 57 percent which is only slightly lower than the 
average proportion of total enrollees recieving grants, 61.4 for the same years.

Summarizing the remaining demographic variables we found just over half the dropouts were single with marriage a close second at almost 40 percent. Seventy-five percent of the dropouts had no children. Nearly three quarters of them were residents of the home state of their school. Most (60.9\%) of the dropouts were known to be unemployed while in school while only 2.6 percent worked over 10 hours per week. However, the employement status of a large portion (29.5 percent) was unknown. About 70 percent of all dropouts were in one of two areas of concentration in school, Generic $(49.4 \%)$ or Casework (20.9\%). Finally, just over half $(52.7 \%)$ of the dropouts had no previous social work experience while 43.2 percent had experience prior to entering school.

In the second major section of the survey, "Reasons for Dropping Out, "the following was found. The general category of "personal" reasons accounted for the most dropouts $(27 \%)$, with "emotional adjustment" being the most frequently reported specific personal reason (13\%). The second largest group (23\%) of dropouts was found in "academic" reasons with academic failure (10.1\%) and "counseled out" (9.3\%) accounting for most of these. Just over 12 percent dropped for "financial" reasons. "Other" reasons accounted for 10.3 percent. Dissatisfaction with the profession of Social Work was reported by 8.3 percent as the primary reason, while 4.2 percent were dissatisfied with their school's curriculum. An identical 4.2 percent dropped for health reasons, .6 percent due to 
pregnancy and 1.5 percent died. There were no responses under "lack of future employment in Social Work." A significant proportion, 9.8 percent, were reported as "reason unknown". 


\section{CRITIQUE}

This section deals with the oversights and problems that we encountered in the construction, administration of the survey instrument as well as those discovered in the analysis of the data.

In the development of our questionnaire we realized that schools with a three or four year program and those utilizing different scheduling methods in academic classes and field practicum i. e. Block Placements, would have difficulty in adapting our questionnaire to their programs. However questionnaires were still mailed to them, leaving this decision up to them.

Administration of the questionnaire was complicated somewhat by the August 2,, 1973 date on the cover letter. Some schools apparently were confused as we did not mail the questionnaires until October. Our original timetable was to mail the questionnaires by the end of August, however at the last moment we decided to postpone mailing until October to avoid burdening the Admissions Departments during registration. We also felt that by delaying until October we would maximize our response rate. Unfortunately because of our oversight August 2, 1973 was not updated to correspond to the actual mailing date. This oversight may have cost us a few responses if schools used the August 22 date as the beginning of our 30 day deadline. They did not actually recieve the questionnaire until the middle of October which was almost a month past our deadline! 
In reference to the deadline, we extended it by almost a month to maximize returns. This proved beneficial as five more questionnaires were returned after our original deadline date.

The administration of the questionnaire: to Directors of Admission may not present an accurate picture of students actual reason for dropping out of school. We realized that this section would be subject to the Director's interpretation of the students'reason for leaving school rather than the students'actual reason. However, it was beyond the scope of this study to contact individual dropouts for this information. We as sumed that the data reported in the demographic section was accurate for the most part. This assumption is partially based on the generally low frequency of "No Responses" in the majority of demographic variables. The variable "Type of Concentration" appeared to cause some of the responding schools difficulty as the No Response frequency was 13.2 percent of the total dropout population. The categories included in this variable were those from CSWE that accounted for over 90 percent of the total enrolled population in 1972 . The high No Response rate could be attributed to misreading the directions or the various schools could or did not adapt the dropout's area of concentration to the headings used by CSWE. Regarding the CSWE headings in "type of concentration," we were unable to utilize CSWE statistics for comparison with the dropout population due to different headings being used each year of the study period. Another oversight occurred in the demographic section. In the variable "Marital Status" we neglected to include the categories 
of Widowed and Separated. These were written in where appropriate by respondents and thus were coded and tallied for the presentation.

The final area where we encountered difficulties was in the compilation and analysis of the data. A major oversight was discovered in the different methods used by us and CSWE in distinguishing students in the variables "year program began" and "class year. "Our original intention was to follow a student from enrollment through graduation the following year, using the year they entered graduate school as the basis of classification. Under this system, a second year student in 1971 who enrolled in 1970 was to be counted as a second year, 1970 dropout. However we found this was not comparable with CSWE statistics as they compiled their data on a calendar year basis. Therefore our 1970 second year dropout by CSWE standards, would actually be a second year 1971 dropout.

If we had utilized our system we would have data on first and second year dropouts in 1970 and 1971 and first year 1972 . However we adopted the CSWE format and ended up with information on first year 1970, first and second year in 1971 and 1972. By doing this we were able to compare our data with CSWE. The changing of our original format after receiving the questionnire: does not invalidate the data but merely shows that there are actually two ways of classifying the same student wi thout misrepresenting the facts.

Other difficulties were encountered in doing the comparisons with CSUfE statistics. We had difficulty in arriving at a consistent enrolled figure in the yearly breakdowns due to reporting errors found in the CSWE 
statistics. Adjustment of the total enrolled population figure for each year was also necessary due to the accreditation status of some schools. Four schools were excluded in 1970 and two in 1971.

In Statistics on Social Work Education, 1970 some of the variables were not divided into first and second classifications thus negating comparison with the 1970 dropout population which included first year only. In 1971 one school had to be excluded from the comparisons on the variable "sex" as CSWE did not report a sex breakdown for that year. Also in 1971 126 enrolled students were not included in the "age" variable due to a reporting error in the CSWE statistics.

In conclusion, none of the problems encountered were of such magnitude as to totally invalidate specific findings. However, they did require additional time and effort to resolve them. We also felt that the design of the questionmire achieved it's purpose. Judging from those returning questiomaires it appeared they encountered no major difficulties in filling them out. We base this contention on the fact that no unfavorable remarks appeared in the "comment" section of returned questionnaires. Also, the "no response" rates in most sections were relatively low indicating that the information sought was relevant. It was noted that refusals to respond were not based on the inappropriateness of the survey instrument. Rather, letters of refusal were based on the schools' lack of information, the inordinate amount of time required to locate the data, or their inability to retrieve it. 


\section{RECOMMENDATIONS}

The suggestions presented in this section can be viewed as three distinct areas. The first considers the need for additional statistical data to be derived from our findings. The second area suggests other variables that could be included in further studies of the Dropout Population. The final part presents our recommendation for the implementation of a Data Collection System on Dropouts.

Although it was beyond the scope of this study, we recognized the importance for additional statistical analysis of our data. For example the factoring of all variables by sex, age and ethnicity could yield some interesting correlations. In fact it would be our recommendation that intercorrelations be completed on all variables to determine what, if any significance the characteristics have to each other. Performing these and other related statistical computations on the demographic characteristics and then factoring by "Reasons for Dropping Out" could, help identify potential problem areas.

There are many variables which may relate to the examination of dropouts that could constitute additional studies. One such study could consist, of canvassing those schools who did not respond to our survey. By sampling the entire or random population of non-respondent schools and comparing it with our data, a more accurate profile could be established. This combined data would also hopefully permit inference, with a reasonable degree of certainty, to the total dropout population 
from Graduate schools of Social Wôrk.

An additional study is needed to further delineate the characteristics of dropouts. It would collect and compare data from the enrolled populations on those variables in our questionnaire that have not already been compared. Other variables not included in our questionnaire could be collected from both the enrolled and dropped populations. These include undergraduate major, grade point average, income, number of years married, and various admission test scores, (S.A.T., M.A.T., G.R.E.).

A nother suggestion for further study is the examination of dropout rates from other graduate and professional schools. This would provide a base for comparing dropout rates in social work with other major fields.

The final recommendation resulting from our survey concerns the need for the implementation of a data collection system on dropouts. Our suggestion is generated by the number of letters that we recieved from those schools unable to participate in our survey. These letters generally indicated that they were unable to participate as they simply did not have the information or the data was difficult to retrieve.

Our conception of such a data collection system would be for CSWE to act as the collecting and dispersal organization. A standardized questionnaire containing essential data on dropouts could be developed and given to all schools. This questionnaire, which would have to protect the students confidentiality, could then be filled out by appropriate administrative staff when a student dropped out of school. The questionnaire could 
then be returned yearly to CSWE accompanying other yearly statistics collected by that organization.

The development of such a system could prove to be very b eneficial to all graduate schools of social work. This information on dropouts could be utilized to examine trends and assess various aspects of the dropout problem. It could also prove helpful to schools in examining their admission procedures. Another potential benefit of this type of information would be identification of potential problem areas for students and the development of responsive policy flexibility. Finally, a decrease in the number of dropouts would financially benefit both the school and students. 


\section{APPENDIX A}

Frequency and Range of Drop Population For All

Responding Schools

1970

1971

\begin{tabular}{|c|c|c|c|c|c|c|}
\hline School & Drops & Enrolled & $\begin{array}{l}\text { Drop Rate } \\
\text { in Percent }\end{array}$ & Drops & Enrolled & $\begin{array}{l}\text { Drop Rate } \\
\text { in Percent }\end{array}$ \\
\hline A. & 4. & 67 & 6.0 & 10 & 118 & 8.5 \\
\hline B. & 3 & 94 & 3.2 & 7 & 193 & 3.6 \\
\hline C. & 4 & 128 & 3.1 & 10 & 226 & 4.4 \\
\hline D. & 1 & 76 & 1.3 & 4 & 156 & 2.6 \\
\hline $\mathrm{E}$. & 6 & 106 & 5.7 & 6 & 173 & 3.5 \\
\hline F. & 7 & 112 & 6.3 & 2 & 197 & 1. \\
\hline G. & 3 & 40 & 7.6 & 2 & 104 & 1.9 \\
\hline $\mathrm{H}$. & 9 & 76 & 11.8 & 13 & 157 & 8.3 \\
\hline I. & 4 & 65 & 6.2 & 3 & 135 & 2.2 \\
\hline J. & $4 *$ & -- & -- & $4 *$ & -- & -- \\
\hline K. & $2 *$ & - & -- & $0 *$ & -- & -- \\
\hline L. & 6 & 40 & 15. & 7 & 69 & 10.1 \\
\hline M. & 1 & 66 & 1.5 & 3 & 151 & 2.0 \\
\hline N. & 1 & 63 & 1.6 & 3 & 145 & 2.1 \\
\hline O. & 3 & 103 & 2.9 & 23 & 202 & 11.4 \\
\hline P. & 4 & 137 & 2.9 & 15 & 279 & 5.4 \\
\hline Q. & 2 & 69 & 2.9 & 14 & 146 & 9.6 \\
\hline R. & 25 & 118 & 21.2 & 40 & 264 & 15.1 \\
\hline S. & 1 & 84 & 1.2 & 1 & 163 & .6 \\
\hline $\mathrm{T}$. & 1 & 85 & 1.2 & 3 & 176 & 1.7 \\
\hline U. & $3 *$ & -- & - & 4 & 61 & 6.6 \\
\hline v. & 6 & 51 & 11.8 & 11 & 109 & 10.1 \\
\hline w. & 1 & 128 & .8 & 6 & 246 & 2.4 \\
\hline $\mathrm{x}$. & 0 & 112 & 0 & 12 & 213 & 5.6 \\
\hline Y. & 9 & 78 & 11.5 & 12 & 291 & 4.1 \\
\hline z. & 16 & 174 & 9.2 & 9 & 175 & 5.1 \\
\hline AA. & 4 & 107 & 3.7 & 7 & 253 & 2.8 \\
\hline BB. & $5 *$ & -- & -- & 3 & 82 & 3.7 \\
\hline $\mathrm{CC}$ & 5 & 58 & 8.6 & 4 & 112 & 3.6 \\
\hline
\end{tabular}

*Dropouts from years not accredited 
APPENDIX A - Con't.

1972

$\begin{array}{ll}\overline{\text { School Drops Enrolled }} & \begin{array}{l}\text { Drop Rate } \\ \text { in Percent }\end{array}\end{array}$

\begin{tabular}{|c|c|c|c|}
\hline A. & 5 & 123 & 4.1 \\
\hline B. & 10 & 186 & 5.4 \\
\hline C. & 7 & 190 & 3.7 \\
\hline D. & 7 & 154 & 4. 5 \\
\hline E. & 3 & 165 & 1.8 \\
\hline $\mathrm{F}$. & 8 & 179 & 4.5 \\
\hline G. & 1 & 129 & .8 \\
\hline $\mathrm{H}$. & 17 & 163 & 10.4 \\
\hline I. & 16 & 160 & 10 \\
\hline J. & 5 & 107 & 4.7 \\
\hline K. & 3 & 109 & 2.8 \\
\hline L. & 15 & 72 & 20.8 \\
\hline M. & 7 & 143 & 4.9 \\
\hline N. & 0 & 147 & 0 \\
\hline 0. & 19 & 205 & 9.3 \\
\hline P. & 10 & 242 & 4.1 \\
\hline Q. & 20 & 152 & 13.7 \\
\hline R. & 44 & 192 & 22.9 \\
\hline S. & 7. & 183 & 3.8 \\
\hline $\mathrm{T}$ & 3 & 182 & 1.6 \\
\hline U. & 6 & 72 & 8.3 \\
\hline V. & 12 & 111 & 10.8 \\
\hline W. & I1 & 255 & 4.3 \\
\hline X. & 5 & 207 & 2.4 \\
\hline $\mathrm{Y}$. & 11 & 217 & 5.1 \\
\hline Z. & 7 & 300 & 2.3 \\
\hline AA. & 9 & 262 & 3.4 \\
\hline BB. & 6 & 92 & 6.5 \\
\hline CC. & 8 & 120 & 6.7 \\
\hline
\end{tabular}




\section{APPENDIX B}

Table 1

Ethnic Characteristics of Enrolled and Dropout Students From Accredited Schools (1970 to 1972), Excluding The University of Puerto Rico

Enrolled

$\mathrm{N}$

Percent of

Enrolled

White

Black

Chicano

Puerto Rican

American Indian

Asian American

Other U.S.

Foreign

N. R.

Totals $\quad 11,092 \quad 100 \%$
$8321 \quad 75$

$1793 \quad 16.2$

$432 \quad 3.9$

$21 \quad .2$

$65 \quad .6$

$201 \quad 1.8$

$19 \quad .2$

$240 \quad 2.2$

-..
Dropped

$\mathrm{N}$

Percent of Dropouts

380

71.4

$92 \quad 17.3$

234.3

2.4

$15 \quad 2.8$

$7 \quad 1.3$

$0 \quad 0$

$8 \quad 1.5$

$5 \quad .9$

$532 \quad i 00 \%$

Table 2

Proportion of Dropout to Enrolled Students by Ethnicity

(1970 to 1972), Excluding The University of Puerto Rico

\section{Percent}

White

Black

4.6

Chicano

5.1

Puerto Rican

5.3

American Indian

9.5

Asian American

23.1

Other U.S.

3.5

Foreign

3. 3 


\section{APPENDIX C}

General Data on Dropouts With and Without The University of Puerto Rico

1970

With U. of Puerto Rico

$$
\underline{N} \text { Percent }
$$

(Class Year Dropped)

$$
\begin{array}{lrr}
\text { First } & 137 & 97.9 \\
\mathrm{~N} / \mathrm{R} & 3 & 2.1 \\
\hline \text { Total } & 140 & 100 \%
\end{array}
$$

(Sex)

$$
\begin{array}{crr}
\text { Male } & 54 & 38.6 \\
\text { Female } & 82 & 58.6 \\
\text { N/R } & 4 & 2.9 \\
\hline \text { Total } & 140 & 100 \%
\end{array}
$$

(Age)

\begin{tabular}{crc}
$25 \&$ Under & 60 & 42.9 \\
$26-30$ & 46 & 32.9 \\
$31-35$ & 14 & 10 \\
$36-40$ & 9 & 6.4 \\
$41-45$ & 4 & 2.9 \\
$46 \&$ Over & 5 & 3.6 \\
N/R & 2 & 1.4 \\
\hline Total & 140 & $100 \%$
\end{tabular}

(Ethnicity)

White

Black

Chicano

Puerto Rican

Amer. Ind.

Asian Amer.

Other U.S.

Foreign

$\mathrm{N} / \mathrm{R}$

Total
Without U. of Puerto Rico

$\underline{\text { Percent }}$

11398.3

\begin{tabular}{cc}
2 & 1.7 \\
\hline 115 & $100 \%$
\end{tabular}

\begin{tabular}{cc}
48 & 41.7 \\
63 & 54.8 \\
4 & 3.5 \\
\hline I15 & $100 \%$
\end{tabular}

\begin{tabular}{cc}
50 & 43.5 \\
36 & 31.3 \\
12 & 10.4 \\
7 & 6.1 \\
4 & 3.5 \\
5 & 4.3 \\
1 & .9 \\
\hline 115 & $100 \%$
\end{tabular}

$\begin{array}{lc}89 & 77.4 \\ 15 & 13 . \\ 1 & .9 \\ 1 & .9 \\ 1 & .9 \\ 5 & 4.3 \\ 0 & .9 \\ 1 . & 1.7 \\ 2 . & 100 \% \\ 115 & \end{array}$


APPENDIX C Con't.

With U. of Puerto Rico

$$
\text { N Percent }
$$

(Marital Status)

$\begin{array}{lcr}\text { Married } & 58 & 48.4 \\ \text { Single } & 73 & 52.1 \\ \text { Divorced } & 6 & 4.3 \\ \text { Widowed } & 1 & .7 \\ \text { Separated } & 1 & .7 \\ \text { N/R } & 1 & .7\end{array}$

Without U. of Puerto Rico

N Percent

Total

$140 \quad 100 \%$

(Number of Children)

$\begin{array}{lrr}0 & 94 & 67.1 \\ 1 & 19 & 13.6 \\ 2 & 11 & 7.9 \\ 3 \text { or more } & 11 & 7.9 \\ \mathrm{~N} / \mathrm{R} & 5 & 3.6\end{array}$

$\begin{array}{rr}84 & 73 . \\ 16 & 13.9 \\ 3 & 2.6 \\ 7 & 6.1 \\ 5 & 4.3\end{array}$

Total

$140 \quad 100 \%$

$115 \quad 100 \%$

(Type of Concentration)

$\begin{array}{lrrrc}\text { Generic } & 55 & 39.3 & 30 & 26.1 \\ \text { Micro Ind. } & 6 & 4.3 & 6 & 5.2 \\ \text { Casework } & 43 & 30.7 & 43 & 37.4 \\ \text { C. O. - Planning } & 7 & 5 & 7 & 6.1 \\ \text { Groupwork } & 9 & 6.4 & 9 & 7.8 \\ \text { Other } & 8 & 5.7 & 8 & 7 . \\ \text { N/R } & 12 & 8.6 & 12 & 10.4\end{array}$

\section{Total}

$140 \quad 100 \%$

115

$100 \%$

(Previous Social Work Experience)

\begin{tabular}{|c|c|c|c|c|}
\hline With Exp. & 67 & 47.9 & 53 & 46.1 \\
\hline W/o Exp. & 63 & 45 & 52 & 45.2 \\
\hline Unknown & 7 & 5 & 7 & 6.1 \\
\hline $\mathrm{N} / \mathrm{R}$ & 3 & 2.1 & 3 & 2.6 \\
\hline
\end{tabular}




\section{APPENDIX C Con't.}

With U. of Puerto Rico

Without U. of Puerto Rico

$\underline{N}$ Percent $\underline{N}$ Percent

(Employment)

Not empl.

Under $10 \mathrm{hrs}$.

$75 \quad 53.6$

$\begin{array}{ll}50 & 43.5\end{array}$

$10-20 \mathrm{hrs}$.

00

64.3

00

over 20 hrs.

$5 \quad 3.6$

$6 \quad 5.2$

Unknown

$49 \quad 35$

54.3

$\mathrm{N} / \mathrm{R}$

$5 \quad 3.6$

$49 \quad 42.6$

54.3

Total

$140 \quad 100 \%$

$115 \quad 100 \%$

(Financial Grants)

With Grants

W/o Grants

$69 \quad 49.3$

$48 \quad 34.3$

Unknown

$\mathrm{N} / \mathrm{R}$

$22 \quad 15.7$

$1 \quad .7$

$46 \quad 40$.

$46 \quad 40$.

$22 \quad 19.1$

$1 \quad .9$

Total

$140 \quad 100 \%$

115

$100 \%$

(Resident of State of School)

$\begin{array}{lrccc}\text { Resident } & 103 & 73.6 & 80 & 69.6 \\ \text { Non-Res. } & 33 & 23.6 & 33 & 28.7 \\ \text { N/R } & 4 & 2.9 & 2 & 1.7\end{array}$

Total

$140 \quad 100 \%$

115

$100 \%$

(Reasons for Dropping Out)

1) Financial

1410

2) Personal

4230

$\begin{array}{rr}4 & 3.5 \\ 41 & 35.7\end{array}$

a) Marital

$5 \quad 3.6$

$18 \quad 12.9$

b) Emot. adj.

64.3

$4,3.5$

c) Spouse mvd.

64.3

d) Crisis

7

5

$\begin{array}{rr}16 & 15.7 \\ 6 & 5.2\end{array}$

65.2

$7 \quad 6.1$ 


\section{APPENDIX C Con't.}

With U. of Puerto Rico

Without U. of Puerto Rico

$$
\text { N Percent }
$$

N Percent

3) Academic Reasons

$38 \quad 27.1$

$31 \quad 27$.

a) failed academ.

$10 \quad 7.1$

$9 \quad 7.8$

b) failed field

42.9

32.6

c) counseled out

$23 \quad 16.4$

$18 \quad 15.7$

d) failed $a \& b$

$1 \quad .7$

1.9

4) Health Reasons

6

4.3

$2 \quad 1.7$

5) Pregnancy

$2 \quad 1.4$

$2 \quad 1.7$

6) Curriculum Dissatisfaction

$1 \quad .9$

7) Dissatisfaction with Profession

139.3

$13 \quad 11.3$

8) Lack of Future Employment

$$
00
$$

00

9) Other Reasons

$11 \quad 7.9$

$10 \quad 8.7$
a) Other work
42.9
b) Death
1.7
c) Marriage

$5 \quad 3.6$
d) Job

$1 \quad .7$

$4 \quad 3.5$

1.9

$4 \quad 3.5$

1.9

10) Reason Unknown

$$
139.3
$$

119.6

11) $N / R$

$0 \quad 0$

Total

$140 \quad 100 \%$

115

$100 \%$ 


\section{APPENDIX D}

General Data on Dropouts with and without The University of Puerto Rico - 1971

With U. of Puerto Rico

$$
\text { N Percent }
$$

(Class Year'Dropped)

First

Second

$\mathrm{N} / \mathrm{R}$

$\begin{array}{ll}194 & 81.9 \\ 40 & 16.9 \\ 3 & 1.3\end{array}$

$237 \quad 100 \%$

$108 \quad 45.6$

$125 \quad 52.7$

$4 \quad$ I. 7
Without U. of Puerto Rico

N Percent

154

40

78.2

3

20.3

1.5

\section{(Sex)}

Male

Female

$\mathrm{N} / \mathrm{R}$

$237 \quad 100 \%$

(Age)

$\begin{array}{lll}\text { Under } 26 & 124 & 52.3 \\ 26-30 & 57 & 24.1 \\ 31-35 & 21 & 8.9 \\ 36-40 & 17 & 7.2 \\ 41-45 & 9 & 3.8 \\ \text { Over } 46 & 5 & 2.1 \\ \text { N/R } & 4 & 1.7\end{array}$

Total

237

$100 \%$

(Ethnicity)

White

Black

Chicano

Puerto Rican

Amer. Ind.

Asian Amer.

Other U.S.

Foreign

$\mathrm{N} / \mathrm{R}$

$\begin{array}{ll}139 & 58.6 \\ 39 & 16.5 \\ 10 & 4.2 \\ 37 & 15.6 \\ 3 & 1.3 \\ 4 & 1.7 \\ 0 & 0 \\ 4 & 1.7 \\ 1 & .4\end{array}$

$139 \quad 58.6$

$39 \quad 16.5$

104.2

$37 \quad 15.6$

$3 \quad 1.3$

4 1. 7

$4 \quad 1.7$

$197 \quad 100 \%$

$\begin{array}{cc}97 & 49.2 \\ 96 & 48.7 \\ 4 & 2 .\end{array}$

197

$100 \%$

$\begin{array}{cc}105 & 53.3 \\ 51 & 25.9 \\ 14 & 7.1 \\ 13 & 6.6 \\ 6 & 3 . \\ 4 & 2 . \\ 4 & 2 .\end{array}$

197

$100 \%$

7.1

6.6

2.

2.

$197 \quad 100 \%$

70.1

$\begin{array}{ll}39 & 19.8\end{array}$

$10 \quad 5.1$

$1 \quad .5$

$3 \quad 1.5$

42.

$0 \quad 0$

$1 \quad .5$

$1 \quad .5$


APPENDIX D Con't.

With U. of Puerto Rico

Without U. of Puerto Rico

N Percent

N Percent

(Marital Status)

Married

Single

Divorced

Widowed

Separated

$\mathrm{N} / \mathrm{R}$
94

122

13

3

3

2
39.7

51.5

5.5

1. 3

1. 3

.8

$\begin{array}{rl}71 & 36 . \\ 106 & 53.8 \\ 13 & 6.6 \\ 2 & 1 . \\ 3 & 1.5 \\ 2 & 1 .\end{array}$

197

$100 \%$

(Number of Children)
0

1

2

3 or more

$\mathrm{N} / \mathrm{R}$
175

17

18

17

10
73.8

7.2

7.6

7.2

4. 2
$142 \quad 72.1$

$16 \quad 8.1$

$16 \quad 8.1$

$13 \quad 6.6$

$10 \quad 5.1$

$237 \quad 100 \%$

197

$100 \%$

(Type of Concentration)
Generic

Micro Interv.

Ca sework

C. O. - Planning

Groupwork

Other

$\mathrm{N} / \mathrm{R}$
109

5

56

21

9

14

23
46

2.6

23.6

8. 9

3. 8

5.9

9.7
6935.

52.5

$56 \quad 28.4$

$\begin{array}{ll}21 & 10.7\end{array}$

94.6

$14 \quad 7.1$

$23 \quad 11.7$
Total

237

$100 \%$

197

$100 \%$

(Previous Social Work Experience) w/ exp.

w/o exp.

Unknown

$\mathrm{N} / \mathrm{R}$

Total
109

121

6

1
46

51.1

2.5

.4

$100 \%$
83

107

6

1
197

\begin{tabular}{ll}
83 & 42.1 \\
107 & 54.3 \\
6 & 3. \\
197 & .5 \\
\hline $100 \%$
\end{tabular}




\section{APPENDIX D Con't.}

With U. of Puerto Rico

W/out U. of Puerto Rico

N Percent

N Percent

(Employment)

not employed

Under $10 \mathrm{hrs}$.

$10-20 \mathrm{hrs}$.

Over $20 \mathrm{hrs}$.

Unknown

$\mathrm{N} / \mathrm{R}$

$\begin{array}{ll}137 & 57.8 \\ 9 & 3.1 \\ 3 & 1.3 \\ 3 & 1.3 \\ 7.8 & 32.9 \\ 7 & 3\end{array}$

97

49.2

9

4.6

$3 \quad 1.5$

$3 \quad 1.5$

$\begin{array}{ll}78 & 39.6\end{array}$

$7 \quad 3.6$

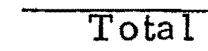

237

$100 \%$

197

$.100 \%$

(Financial Grants)

With Grants

W/o Grants

Unknown

132

$\mathrm{N} / \mathrm{R}$

93

10

2

55.7

39.2

4.2

.8

$100 \%$

70.9

23.2

5.9

168

55

14

$N / R$

237

Total

$100 \%$

197

97

49.2

88

10

44.7

2

5.1

1.

$197 \quad 100 \%$

(Part B) Reasons for Drops

1) Financial Reasons 32

2) Personal Reasons 63

13.5

12

133

67.5

55

27.9

9

4.6

a. Marital

b. Emot, Adjust.

4

26.6

60

6.1

c. Spouse moved

1. 7

31

13.1

d. Crisis

3.8

e. Other

5

14

2. 1

5.9

4

30

9

4

$100 \%$

$100 \%$




\section{APPENDIX D Con't.}

With U. of Puerto Rico

With U. of Puerto Rico
W/o U. of Puerto Rico

$\underline{N}$ Percent $\quad$ Percent

Academic Reasons

Total $257 \quad 24.1$

49

24.9
a) failed academically 26
11.
b) failed field
9
3.8
c) counseled out
8.9
d) failed a \& b

$\begin{array}{lr}21 & 8.9 \\ 1 & .4\end{array}$
24
12.2
9
4.6
$15 \quad 7.6$
4
1
.5

Health Reasons

9

3.8

8

4. 1

Pregnancy

1.4

1

.5

Curriculum Dissatisfaction 11

4.6

ll

5.6

Dissatisfaction w/ Profession

$\begin{array}{lll}6.8 & 16 & 8.1\end{array}$

Lack of Future employment 0

0

0

0

Other

\begin{tabular}{|c|c|c|c|c|}
\hline Total & 28 & 11.8 & 22 & 11.2 \\
\hline a) other unknown & 11 & 4.6 & 6 & 3.0 \\
\hline b) Death & 6 & 2.5 & 6 & 3.0 \\
\hline c) Marriage & 5 & 2.1 & 4 & 2.0 \\
\hline d) Job & 6 & 2.5 & 6 & 3.0 \\
\hline
\end{tabular}

Reason Unknown

20

8.4

18

9.1

$\mathrm{N} / \mathrm{R}$

$0 \quad 0$

$0 \quad 0$ 


\section{APPENDIX E}

General Data on Dropouts With and Without The University of Puerto Rico - 1972

With U. of Puerto Rico

Without U. of Puerto Rico

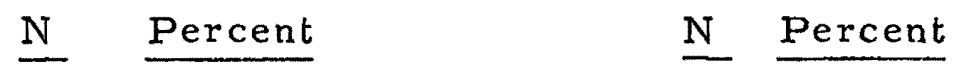

(Class Yr. Dropped)

First

Second

$\mathrm{N} / \mathrm{R}$

$\begin{array}{cc}246 & 87.2 \\ 35 & 12.4 \\ 1 & .4\end{array}$

$202 \quad 84.9$

$35 \quad 14.7$

1.4

Total

(Sex)

Male

Female

$\mathrm{N} / \mathrm{R}$
113

165

4
$100 \%$

40.1

58.5

1. 4
238

$100 \%$

\section{Total}

(Age)

$25 \&$ Under
$26-30$
$31-35$
$36-40$
$41-45$
$46 \&$ OVer
N/R

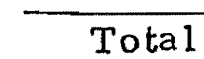

(Ethnicity)

White

Black

Enicano

Puerto Rican

Amer. Ind.

Asian Amer.

Other U.S.

Foreign

$\mathrm{N} / \mathrm{R}$
162

63

20

9

11

10

7
$100 \%$
$101 \quad 42.4$

$133 \quad 55.9$

$4 \quad 1.7$
282

238

$100 \%$

3.2

3. 9

3. 5

2. 5

131

55.

$57 \quad 23.9$

$16 \quad 6.7$

$6 \quad 2.5$

114.6

$10 \quad 4.2$

$7 \quad 2.9$

$282 \quad 100 \%$

238

$100 \%$

170
39
12
43
7
3
0
6
2

60.3

$170 \quad 71.4$

$\begin{array}{lr}39 & 13.8 \\ 12 & 4.3\end{array}$

$39 \quad 16.4$

$43 \quad 15.2$

12

5.

$7 \quad 2.5$

$3 \quad 1.1$

00

62.1

2.7

$0 \quad 0$

$7 \quad 2.9$

31.3

00

$5 \quad 2.1$

$2 \quad .8$ 


\section{APPENDIX E Con't.}

With U. of Puerto Rico

Without U. of Puerto Rico

$$
\text { N Percent }
$$

N Percent

(Marital Status)

Married

Single

Divorced

Widowed

Separated

Unknown
109

.158

8

2

3

2
38.7

56.

2. 8

.7

1. 1

.7
$95 \quad 39.9$

$128 \quad 53.8$

$8 \quad 3.4$

$2 \quad .8$

$3 \quad 1.3$

$\begin{array}{ll}2 & .8\end{array}$

\begin{tabular}{lllll}
\hline Total & 282 & $100 \%$ & 238 & $100 \%$
\end{tabular}

(Number. of Children)

$\begin{array}{lrrrr}0 & 221 & 78.4 & 184 & 77.3 \\ 1 & 26 & 9.2 & 23 & 9.7 \\ 2 & 12 & 4.3 & 12 & 5 . \\ 3 & 16 & 5.7 & 12 & 5 . \\ \mathrm{N} / \mathrm{R} & 7 & 2.5 & 7 & 2.9\end{array}$

Total

282

$100 \%$

$238 \quad 100 \%$

(Type of Concentration)

$\begin{array}{lccrr}\text { Generic } & 162 & 57.4 & 118 & 49.6 \\ \text { Micro Inter. } & 18 & 6.4 & 18 & 7.6 \\ \text { Casework } & 39 & 13.8 & 39 & 16.4 \\ \text { C. O. - Plann. } & 23 & 8.2 & 23 & 9.7 \\ \text { Group Work } & 10 & 3.5 & 10 & 4.2 \\ \text { Other } & 16 & 5.7 & 16 & 6.7 \\ \text { N/R } & 14 & 5 . & 14 & 5.9\end{array}$

Total

282

$100 \%$

$238-100 \%$

(Previous Social Work Experience)

$\begin{array}{lccrc}\text { With exp. } & 109 & 38.7 & 92 & 38.7 \\ \text { W/out exp. } & 164 & 58.2 & 137 & 57.6 \\ \text { Unknown } & 4 & 1.4 & 4 & 1.7 \\ \text { N/R } & 5 & 1.8 & 5 & 2.1\end{array}$




\section{APPENDIX E Con't.}

With U. of Puerto Rico

Without U. of Puerto Rico

$\underline{N} \underline{N} \quad \underline{N} \quad \underline{\text { Percent }}$

Employment

Not Emp.

187

Under $10 \mathrm{hrs}$.

3

10-20 hrs.

12

Over 20 hrs.

4

Unknown

$\mathrm{N} / \mathrm{R}$

68

8

66.3
1.1
4.3
1.4
24.1
2.8

147

61.8

2

.8

12

5.

1.7

$68 \quad 28.6$

52.1

Total

282

$100 \%$

238

$100 \%$

Financial Grants

W/Grants

W/o Grants

163

111

57. 8

124

52.1

Unk.

4

39.4

$\mathrm{N} / \mathrm{R}$

1. 4

106

44.5

4

1. 4

4

1. 7

1. 7

\section{Total}

282

$100 \%$

238

$100 \%$

Resident of State of School

Resident

Non-Resident

$\mathrm{N} / \mathrm{R}$
196

83

3
69.5

29.4

1. 1
152

83

3
63.9

34.9

1. 3

\section{Total}

282

$100 \%$

238

$100 \%$

(Part B) Reasons For Dropping Out

$\begin{array}{lrrrr}\text { 1) Financial Reasons } & 35 & 12.4 & 18 & 7.6 \\ \text { 2) Personal Reasons } & 73 & 25.9 & 71 & 29.8 \\ \text { a) marital } & 10 & 3.5 & 10 & 4.2 \\ \text { b) emotional adj. } & 37 & 13.1 & 37 & 15.5 \\ \text { c) spouse moved } & 8 & 2.8 & 7 & 2.9 \\ \text { d) crisis } & 9 & 3.2 & 9 & 3.8 \\ \text { e) other } & 9 & 3.2 & 8 & 3.4\end{array}$


APPENDIX E Con't.

With U. of Puerto Rico

Without U. of Puerto Rico

N Percent

N Percent

Academic Reasons $\quad 56$

19.9

$48 \quad 20.2$

a) failed academ. $\quad 30$

10.6

28

11.8

b) failed field

2.1

$6 \quad 2.5$

c) counseled out 18

6.4

d) failed a \& b

.7

12

5 .

2

.8

Health Reason

13

4. 6

10

4.2

Pregnancy

2

.7

2

.8

Curriculum Dissatisfaction

16

Dissatisfaction w/ Profession

5.7

16

6.7

25

8.9

25

10.5

Lack of future Employment

$$
0
$$

0

0

0

Other
a) other unknown
b) Death
c) Marriage
d) $\mathrm{Job}$

28

9. 9

26

10.9

12

4. 3

10

4.2

1. 1

3

1. 3

7

2.5

2. 9

2.1

7

6

2.5

Reason Unknown

32

11. 3

20

8.4

$\mathrm{N} / \mathrm{R}$

2

.7

2

.8 


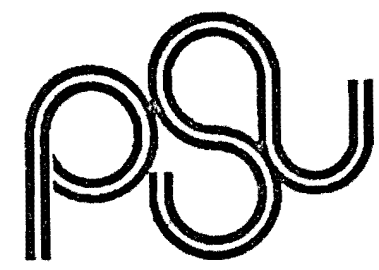

August 22, 2973

PORTLAND
STATE
UNIVERSITY
p. O. box 751
ortland, oregon
97207
$503 / 229-4712$

school of social work

\section{Dear Sir:}

We are undertaking a survey of all graduate schools of social work in the nation to examine recent trends in drop-out rates from master's degree programs. This survey is a graduate thesis project in collaboration with the Admissions Office of the Portland State University School of Social Work.

Through means of a questionnaire we are seeking to gather data on selected variables in order to determine the characteristics of dropout students and their reasons for dropping out. To facilitate this task we are asking your assistance in filling out the enclosed questionnaires.

The process of entering graduate school is expensive and demanding of both students and faculty. It is hoped that the results of this survey will be useful in the planning and modification of master's programs in social work and will help eliminate the pain and frustration accompanying an incompleted program of graduate study.

Individual schools will not be identified in the final presentation of the findings. You will note that your school has been assigned a code mumber. This number will be used only by the researchers for compilation of data and correspondence.

If you have any other pertinent information concerning your institution's drop-outs, we would appreclate receiving a copy of such.

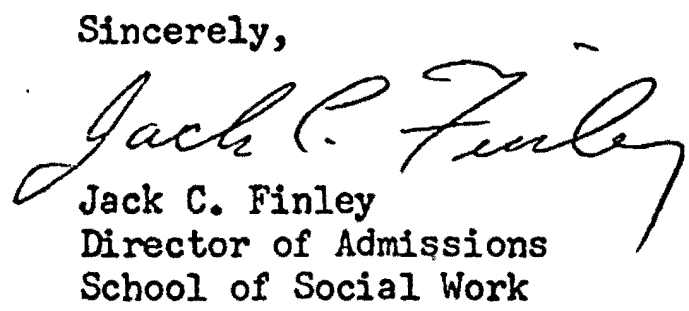

JCF:bc

Enclosures 
General Directions

\section{Definition of a drop-out:}

For the purpose of this survey a drop-out is defined as a full time student who was accepted in your master's program in social work and enrolled, but failed to graduate from your institution.

Since thir survey is primarily intended to gather data about students leaving the field of social work, students who transferred to another school of social work will not be considered drop-outs.

Part time students will not be included in the scope of this survey.

Please note: On each questionnaire page there is room for information on two dropout students.

Student \#__: Please do not fill in this space. It will be used by the researchers ! after the questionnaires are returned.

\section{Specific Directions}

\section{Part A}

The majority of the information requested in Part $A$ coincides with that found in the annual C.S.W.E. report Statistics on Social Work Education. This is intended to allow for a comparison and contrast of the drop-out population with the master's level studeni population as a whole.

The students this survey is concerned with are those who began their first year of grad, uate study at the master's level in 1970, 1971 and 1972 and those who began their second year in 1971 and 1972.

Please check one item in each applicable category (1 through 12) in Part A.

1. Year program began:

Please check the year in which the student began his first year of graduate study.

2. Class year dropped:

Check the class year during which the student terminated his program. Students who! successfully completed their first year but failed to return the second year will be considered first year drop-outs.

8. Type of Concentration:

The six areas of concentration specified are those containing the highest number of students in table 254 of the 1972 C.S.W.E. Statistics on Social Work Education. 
9. Previous social work experience:

At least one year of full time employment in the field of social services.

\section{Part B}

We are aware that there may be several interrelated factors involved in a student's decision to drop out of school. However, we ask that you select the ultimate or most significant reason as stated by the student or determined by the school rather than a precipitating event.

The definitions offered here for the various reasons for dropping out are certainly open to interpretation. We offer them as a general guide and hope they will be used as such.

Please check or specifiy only one reason in Part $B$.

1. Financial:

- Student chose or was forced to drop out due to financial pressure.

2. Personal:

Marital - Student dropped out due to stress resulting from dysfunction within the marital relationship.

Emotional Adjustment - Inability of student to resolve interpersonal or intrapersonal conflicts and/or adjust to the pressures of graduate study resulting in discontinuation of the program.

Spouse Moved - In the absence of serious marital problems the student discontinues program to accompany spouse on move necessitated by job transfer, health, etc.

Crisis - A sudden acute event; the impact or resolution of which necessitated the student dropping out of school (e.g. death in family).

3. Academic:

Failed Academically - Failure of student to maintain minimum G.P.A. or other standards set by school for course work.

Failed in Field Practicum - Failure of student to perform satisfactorily in field practicum.

Counseled Out - Student acted upon advice of school to discontinue due to impending failure or unsatisfactory performance.

4. Health:

Student discontinued program due to physical health problems.

5. Pregnancy:

Females only. 


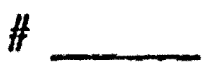

Name

Position

Address

Would you like a copy of the results of this study? Yes No

Comments

Please return only this page and the questionnaire. 
We would appreciate all questionnaires to be returned within thirty (30) days. If you find that additional questionnaire sheets are needed, please phone or write:

Jack Finley, Director of Admissions

Port land State University

School of Social Work

724 S. W. Harrison

Portland, oregon 97201

(503) $229-4712$ 
Student $\#$

A.

1. Year program bef̧an: $1970 \quad 1971 \quad 1972$

2. Class year dropped: First year _ Second year

3. Sex: Male Female

4. Age: Under $\overline{26} \quad 26-\overline{30} \quad 31-35 \quad 36-40 \quad 41-45$ Over 45

5. Ethnicity: :hite Black Chicano _ Puerto Rican Amer. Ind.

6. Marital Status: Married- Single. Divorced

7. Children at home: Cne Two Three or more

8. Type of Concentration: Generic Micro Intcrvention Casework

Communily Org.-Planning Groupwork _ Other

10. Employed while in school: ho Under $10 \mathrm{hrs.}$ Unknown $10-20 \mathrm{hrs}$.

Over $20 \mathrm{hrs}$. Unknown

11. Financial grant: Yes No Unknown

12. Resident of state of school: $\overline{\text { Yes }}$ No

B. Reasons For Dropping Out

1. Financial

2. Personal: Marital Fmotional Adjustment Other Personal (specify)

3. Academic: Failed academically Failed field practicum Spouse Moved Crisis

4. Health

5. Pregnancy

6. Curriculum dissatisfaction

7. Dissatisfaction with social kork profession

8. Lack of future employment ond advancement in social work

9. Other reason (specify)

10. Reason unknown

QUESTTONNAIRE

Student \#

A.

1. Year program began: $1970 \quad 1971 \quad 1972$

2. Class year dropped: First year _ Second year

3. Sex: Male Feriale

4. Age: Under $26 \quad 26-\overline{30} \quad 31-35 \quad 36-40 \quad 41-45$

5. Ethnicity: White Black Chicano Puerto Rican Over $45 . \overline{\text { And. }}$

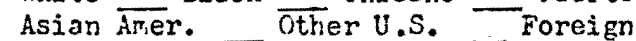

6. Marital Status: Married Single Divorced

7. Children at home: One Two Three or more

8. Type of Concentration: Generic - Micro Intervention Casework

Community Org.-Planning Groupwork Other

9. Previous social work experience: Yes No Unknow

10. Employed while in school: No Under $10 \mathrm{hrs.} 10-20 \overline{\mathrm{hrs}}$.

11. Financjal grant: Yes No Unknown

12. Resident of state of school: Yes № Unknown

B. Reasons For Dropping Out

1. Financial

2. Personal: Firital Fmotional Adjustment Other Personal (specify)

3. Acedemic: Failed acadomically Faíled field practicum Spouse Yoved Crisis

4. Health

5. Pregnancy

6. Curriculum dissatisfaction

7. Dissatisfaction with social work profession

8. Lack of future employment and advancement in social work

9. Other reason (specily)

10. Reason unknown 